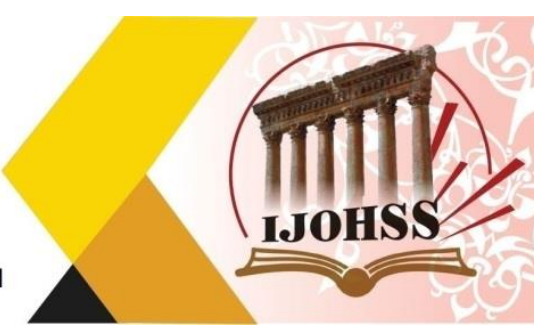

\title{
مدى إلزامية مبادئ الحوكمة على شركات المساهمة

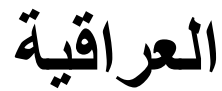 \\ (دراسة مقارنة)
}

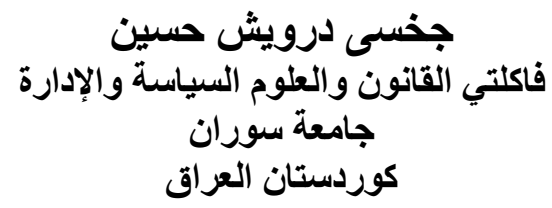

البريد الاكتروني: Jekhsee2994@gmail.com

|لماخص

إن الأزمات المالية والاقتصادية التي واجنتها الثركات التجارية، ولا سيما العملاقة خلال الفترة الأخيرة في العديد من الدول العالم نتيجة التلاعب بمصداقية القوائم المالية للشركات المساهمة، قد دفعت الجهات المعنية الوطنية والمنظمات الدولية ومشرعو القانون في هذه الدول إلى اجر اء دراسات معمقة لإيجاد حلول مناسبة لتجنب هذه الأزمات وتحقيق الإستقرار في الأسواق الوطنية والدولية. وكانت ثمرة هذه الجهود هو تبنى نظام

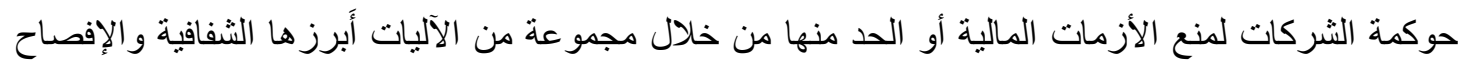
الحقيقي عن المعلومات المالية وغير المالية وتفعيل الرقابة الداخلية والخارجية على أعمالها للحد من الغش و التلاعب فيها فضلاً عن تفعيل دور مجلس الإدارة فيها لحماية حقوق المساهمين والمتعاملين مع الثركة وقد تجسدت تلك الجهود في تشريع نظام خاص بالحوكمة و إلزام الثركات بالعمل بها أو تعديل أو تشريع قوانين جديدة للشركات عن طريق تبني قو اعد وآليات الحوكمة في هذه القو انين. الكلمات المفتاحية: الثركات المساهمة، نظام الحوكمة، معايير (OECD). 


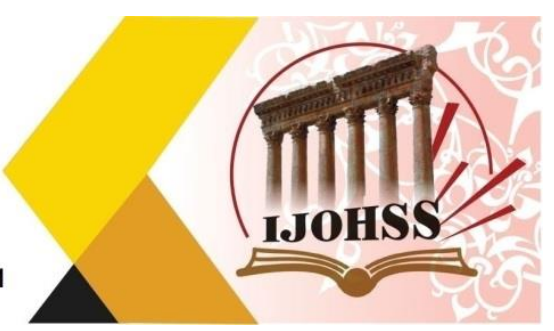

\title{
The Extent to which Corporate Governance Principles are Mandatory for Iraqi Joint Stock Companies (A comparative study)
}

\author{
Jakhsi Darwish Hussein \\ Faculty of Law, political science, and administration \\ Soran University \\ Iraqi Kurdistan \\ Email: Jekhsee2994@gmail.com
}

\begin{abstract}
The financial and economic crises faced by commercial companies, especially giants, during the recent period in many countries of the world, as a result of manipulating and the credibility of the financial statements of shareholding companies has prompted the concerned national authorities, international organizations and legislators in these countries to conduct in-depth studies to find appropriate solutions to avoid these crises and achieving stability in the national and international markets. The result of these efforts was the adoption of the corporate governance system to prevent or reduce financial crises through a set of mechanisms, most notably transparency and real disclosure of financial and non-financial information and activating internal and external control over its business to reduce fraud and manipulation, as well as activating the role of the Board of Directors in it to protect the rights of shareholders And those dealing with the company.

These efforts were embodied in either legislation a system of governance and obligating companies to work with it, or amending or enacting new companies laws by adopting the rules and mechanisms of governance in these laws.
\end{abstract}

Keywords: joint stock companies, governance system, (OECD) standards. 


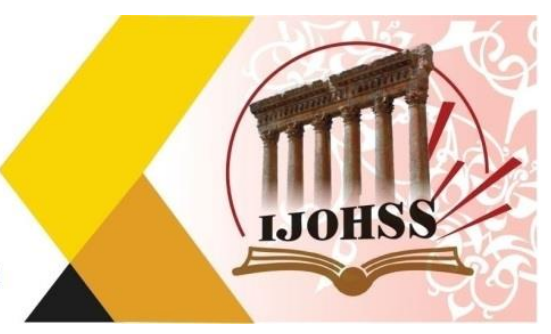

المقدمة

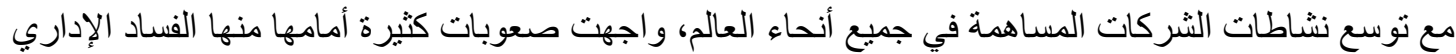

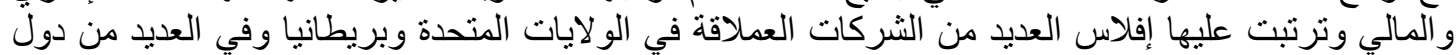

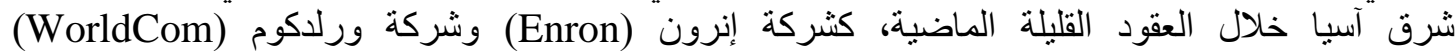

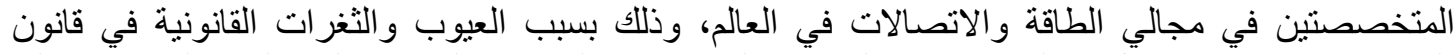

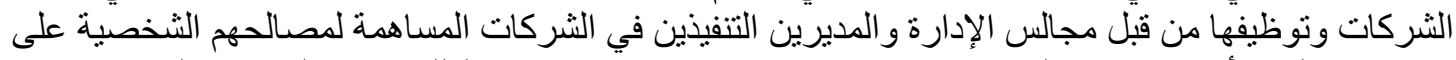

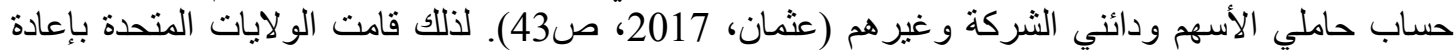

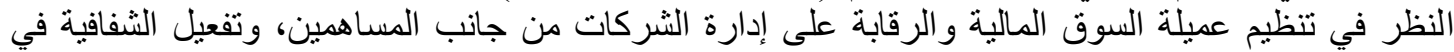

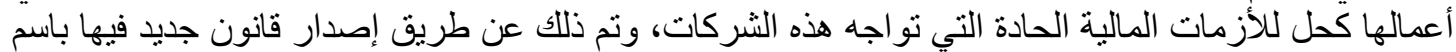

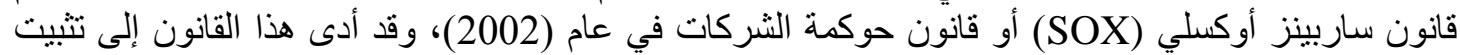

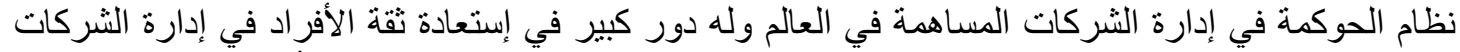

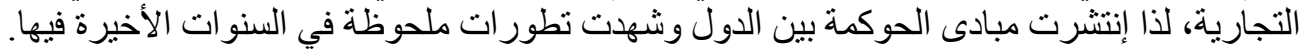

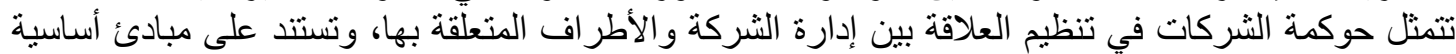

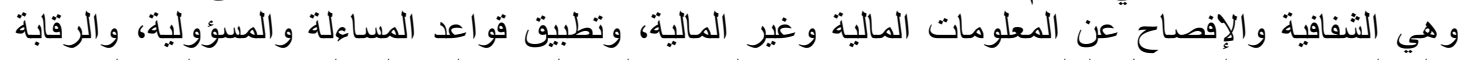

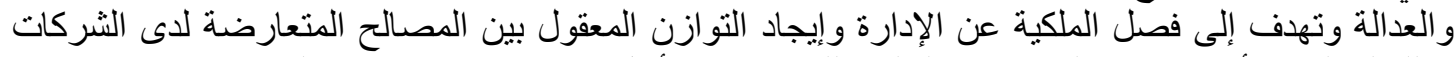

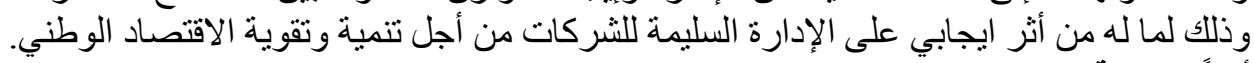

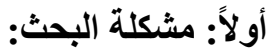

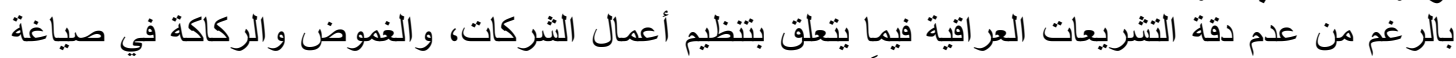

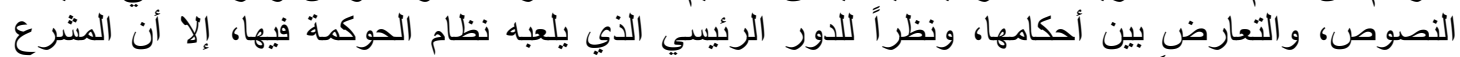

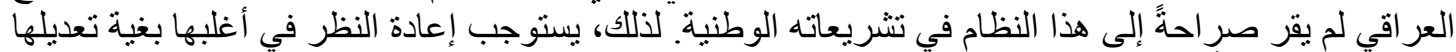

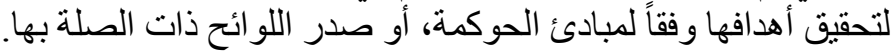

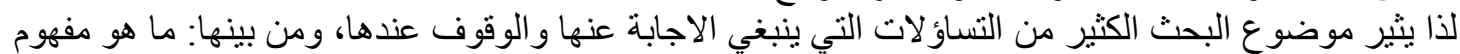

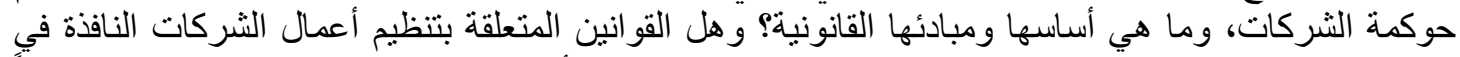

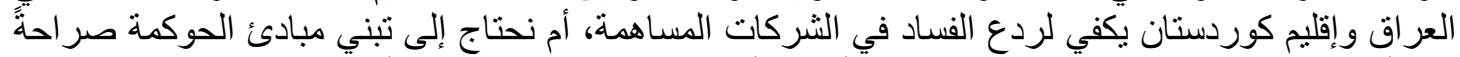

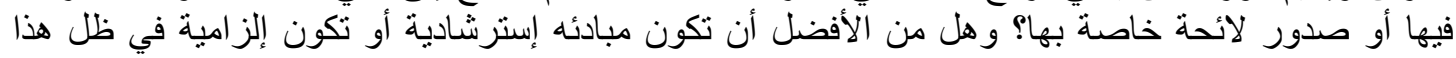

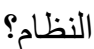

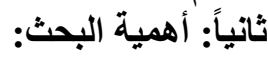

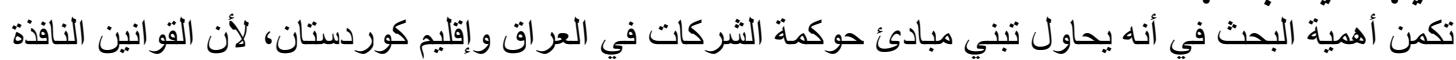

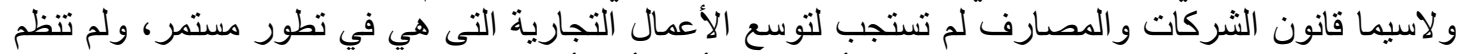

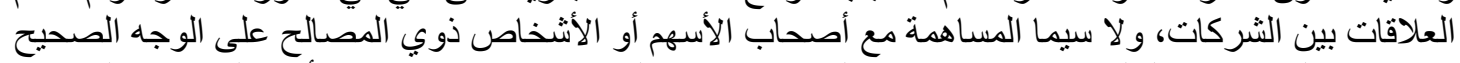

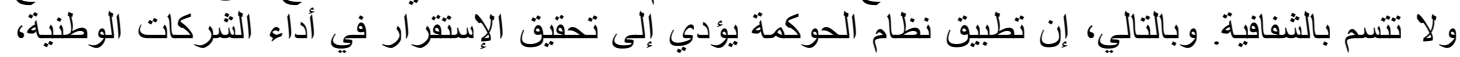
وجذب المستثمرين، وتنمية النمو الاقتصادي.

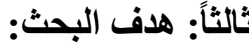

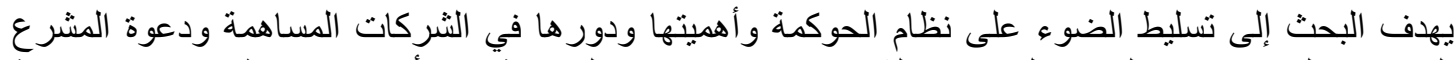

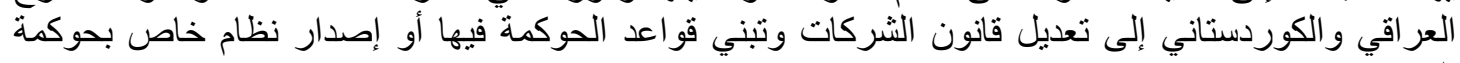

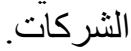

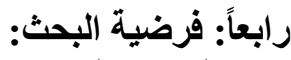
ييني البحث على فرضئ فئية مفادها (إن إلز امية مبادئ الحوكمة في التشريعات الوطنية يخلق بيئة إجبارية لإدارة

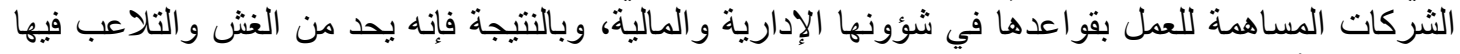
ويخلق بيئة آمنة للمتعاملين مع الثركات).

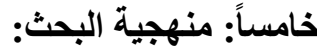

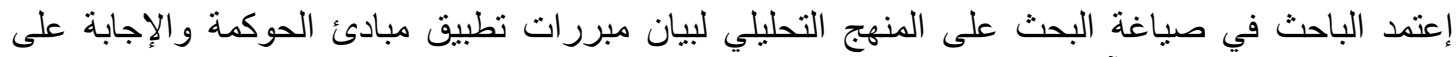

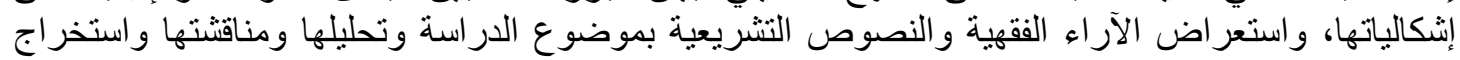




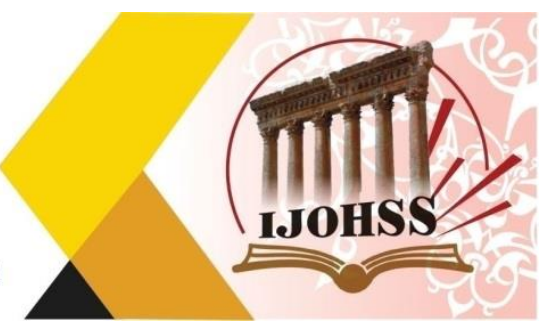

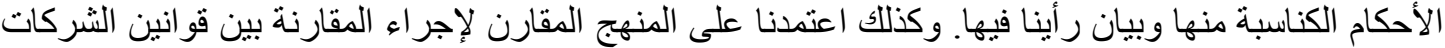

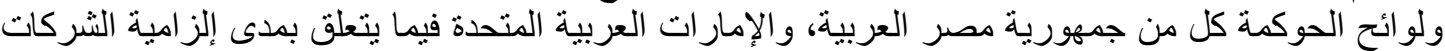

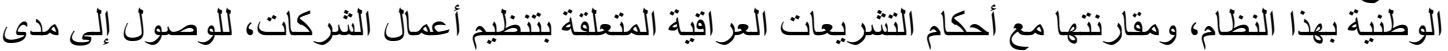

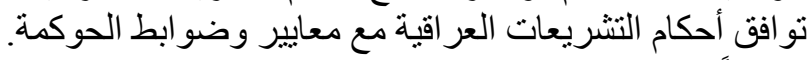

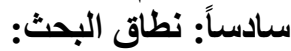

يقتضي موضوع هذا البحث دراسة ماهية نظام الحوكمة، ومبادئها القانونية، ومن ثم التطرق إلى مألى مدى إلزامية

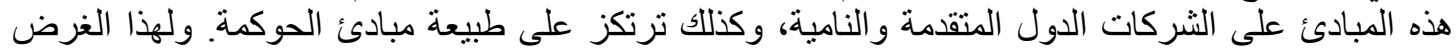

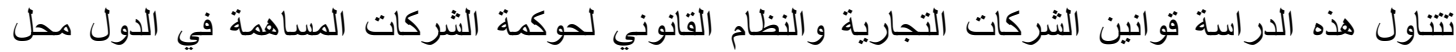
الدراسة وهي (جمهورية مصر العربية، الإمارات العربية المتحدة وجمهورية العراق العية الإتحادية) وتحليلها

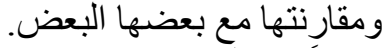

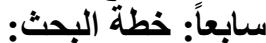

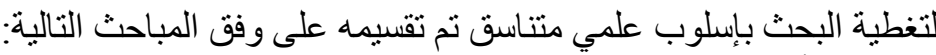
المبحث الأول: ماهية حوكمة الثركات الثبات المساهمة المبحث الثاني: مبادئ الحوكمة في التشريعات الوكنية الوطنية

\section{المبحث الأول \\ ماهية حوكمة الشركات المساهمة

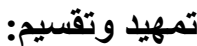

ظهرت فكرة الحوكمة بسبب عدة أزمات مالية هزت الأوضاع الاقتصادية للدول المتقدمة و أدت إلى إنهيار العديد

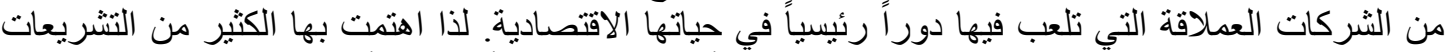

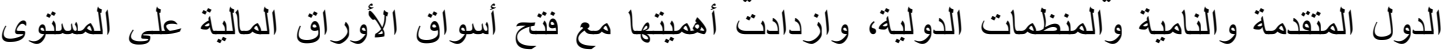

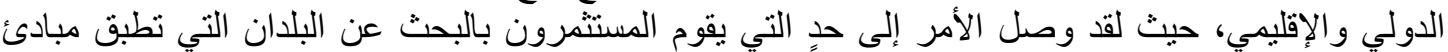

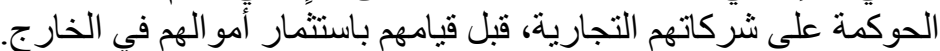

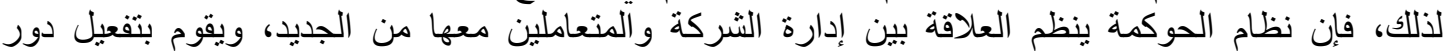

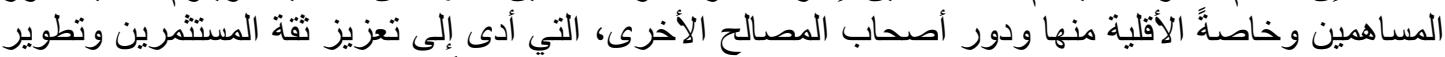

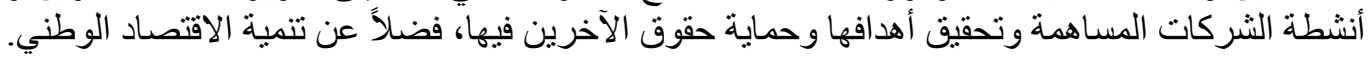

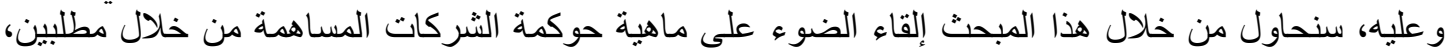
حيث سنوضح في المطلب الأول مفهوم حوكمة الثركات وخصائصها، ونبين في المطلب الثناني أهمية حوكمة الثة الثالية الثركات و أهدافها. المطلب الأول مفهوم حوكمة الشركات المساهمة وخصائصها

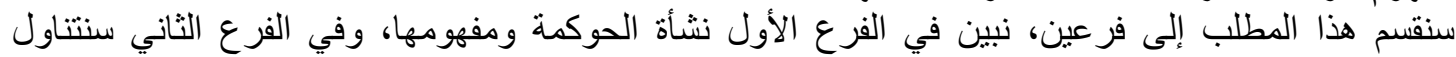

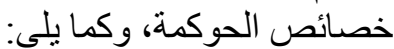
الفرع الأول: نشأة الحوكمة ومفهومياكيا

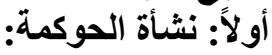

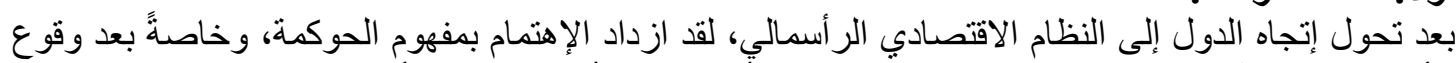

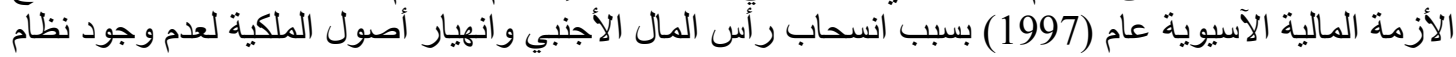

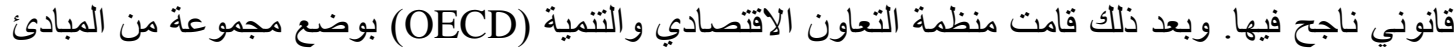

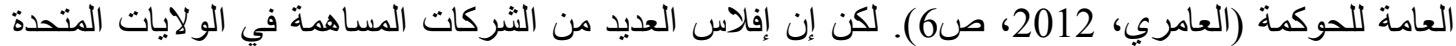

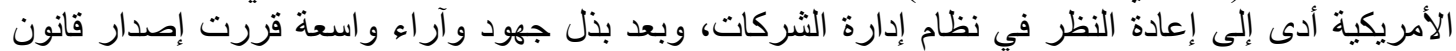
سار ابانس أوكسلي (Sarbanes - Oxley Act) في عام (2002). 


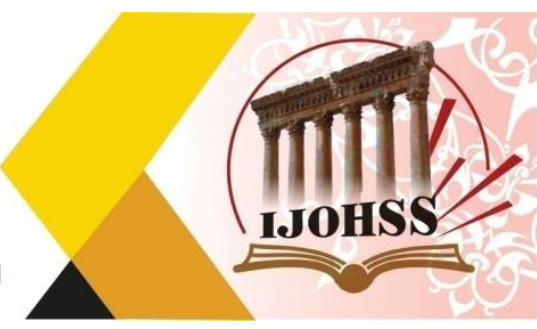

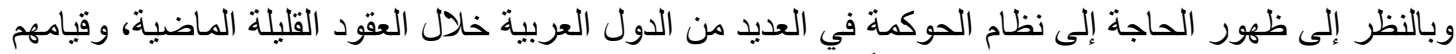

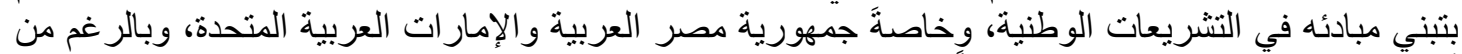

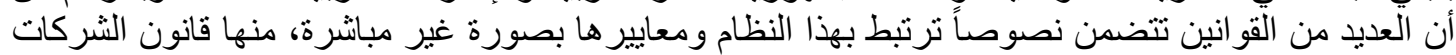

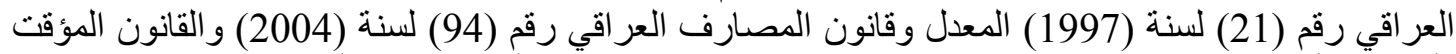

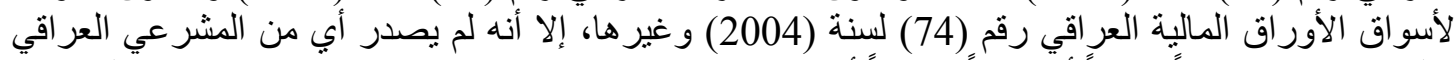

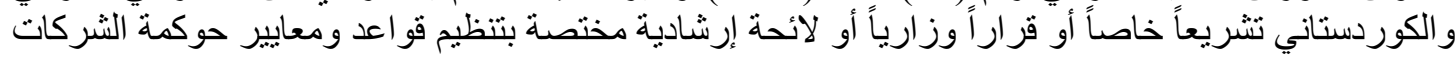

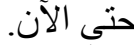

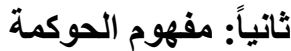

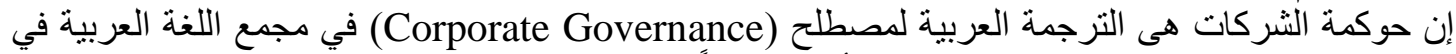

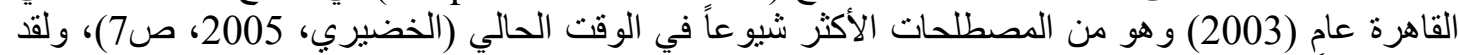

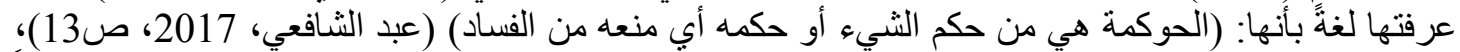

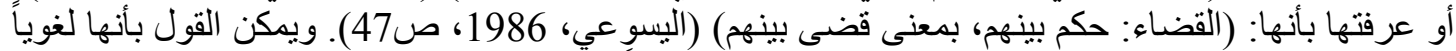

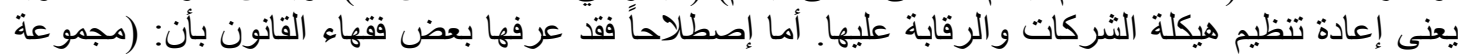

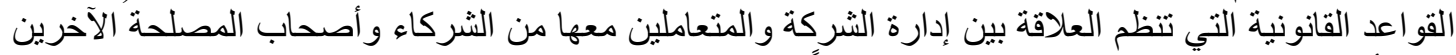

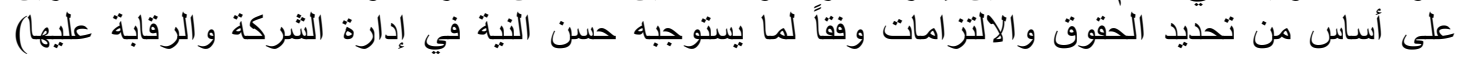

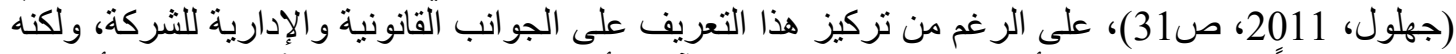

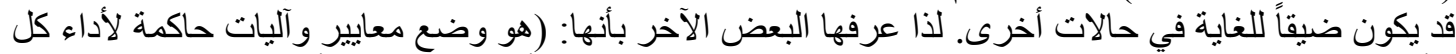

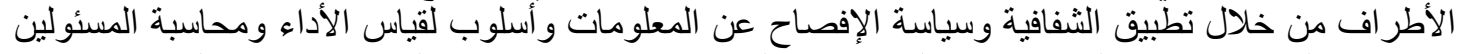

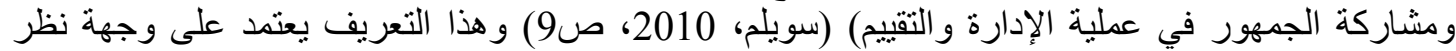
أوسع للحوكمة حيث يركز على في مبادئها.

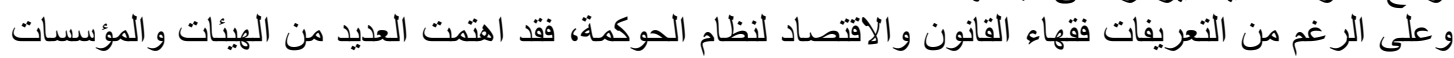

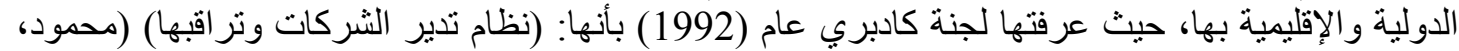

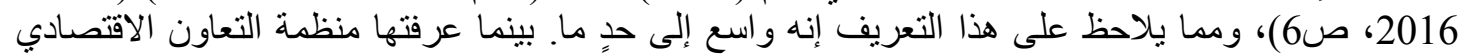

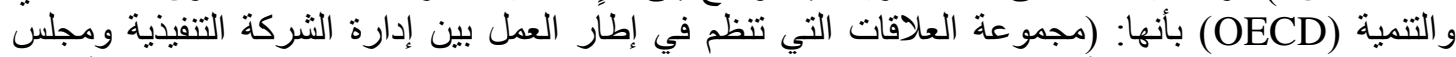

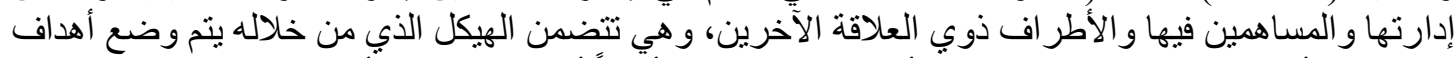

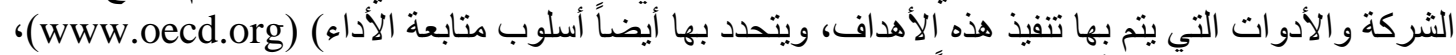

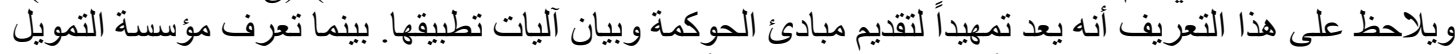

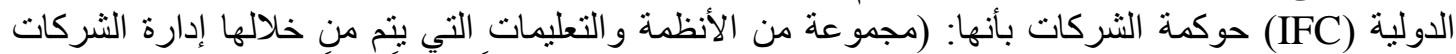

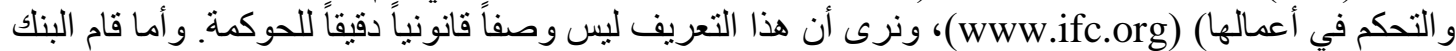

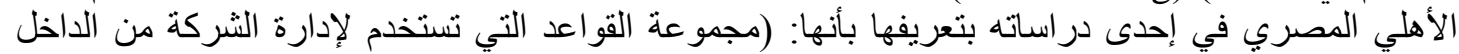

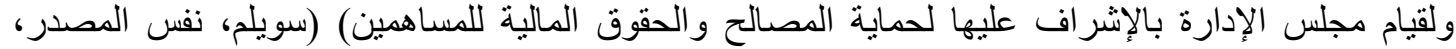
من خلال هذه التعاريف نرى بأن حوكمة الثركات هي ليست مجرد قرار ات لمدر اءو ورؤساء الثركات التجارية،

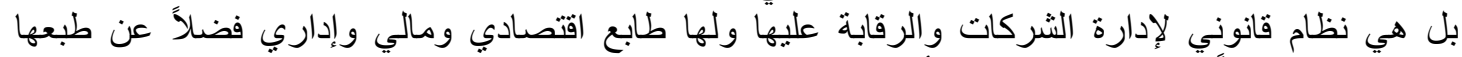

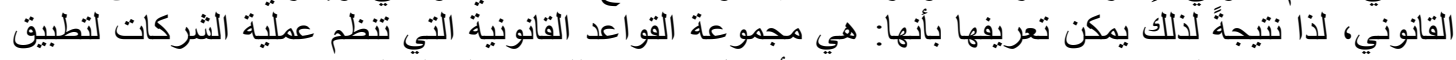

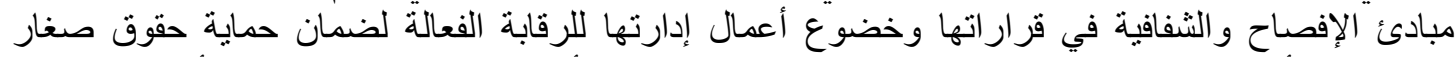

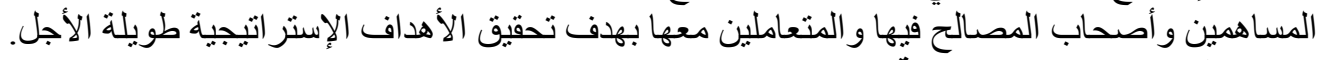

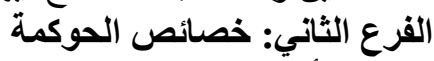

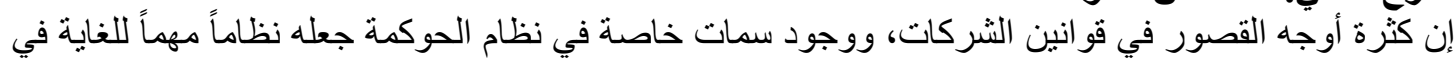

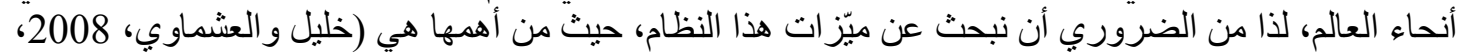
ص22) أ. الإنضباط: أي إتباع السلوك الأخلاقي المناسب والصحيح من خلال الالتزام بالأهداف الرئيسية للشركة بوضوح و إصدار بيانات واضحة للجمهور و التقدير السليم لتكلفة رأس المال. 


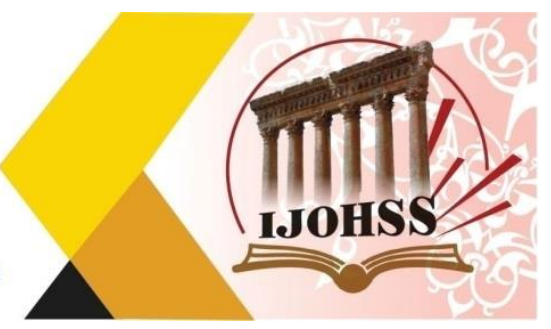

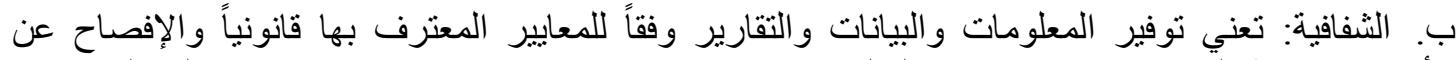

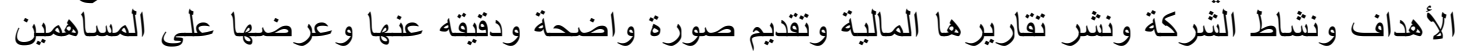
و الأطر اف الأخرى للإطلاع علئها

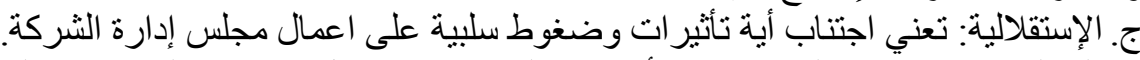

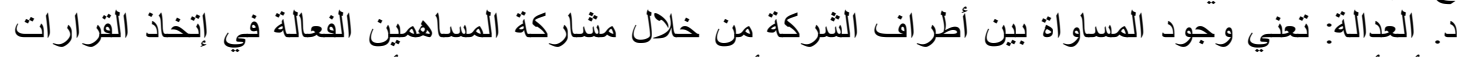

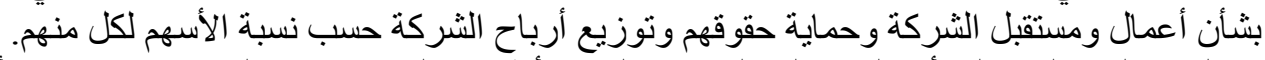

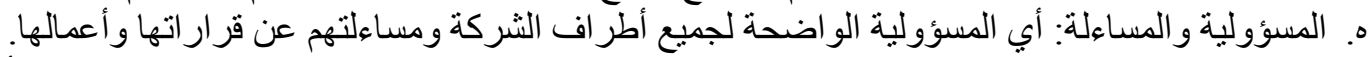

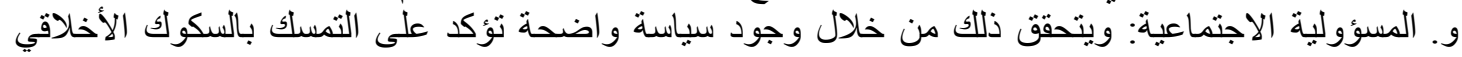

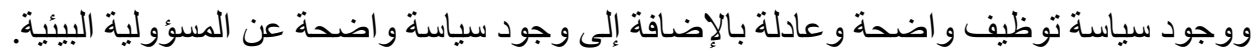

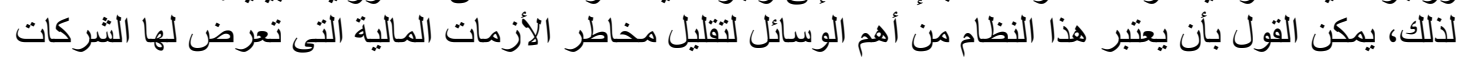

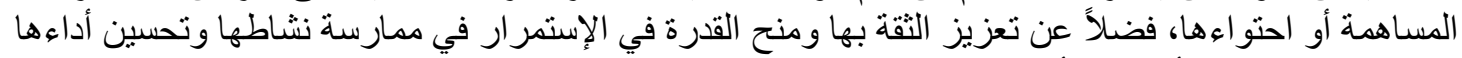
لضمان الوصول إلى أهدافها وأهداف المتعاملين معها. المطلب الثاني انوي أهمية حوكمةًّة الثركات وأهدافها سنقسم هذا المطلب إلى فركة فين، وألى وسنتحدث في الفرع الأول منه أهمية الحوكمة، وسنتكلم في الفرع الثاني في

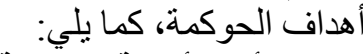
الفرع الأول: أهمية الحوكمة الهمبة مع تطبيق هذا النظام في الثركات الثركة المساهمة الوطنية، تظهر أهميته في كل الجوانب القانونية والاقتصادية

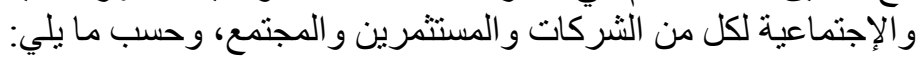

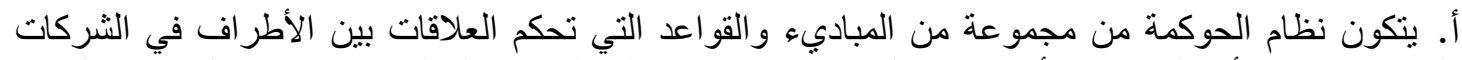

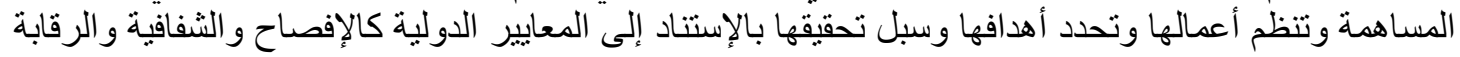

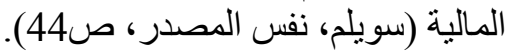

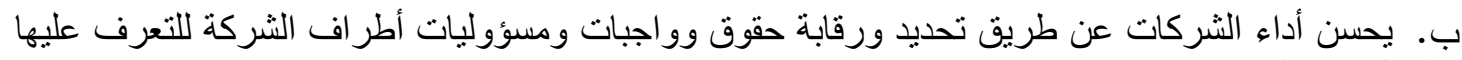

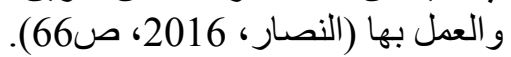
ج. نوفر الضمانات القانونية للمساهمين و أصحاب المصالح الصالح الآخرين التي كانت غير واردة في القو انين الأخرى

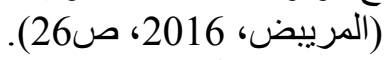

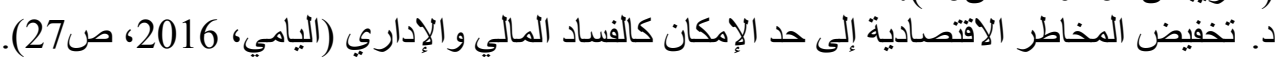

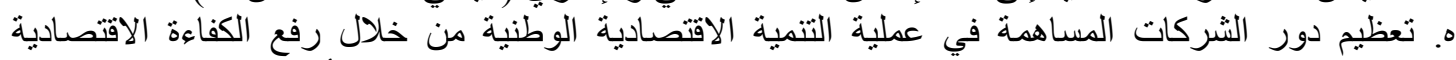

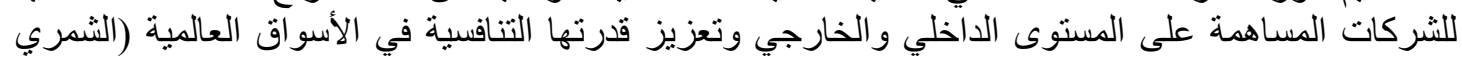

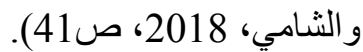

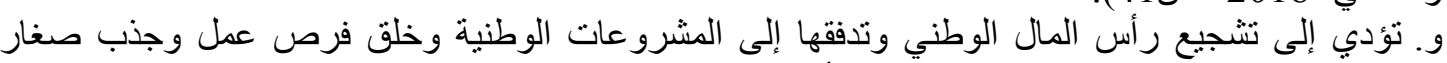

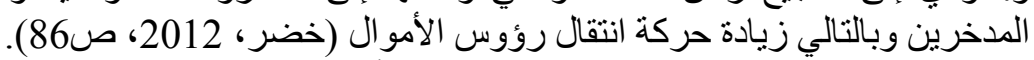

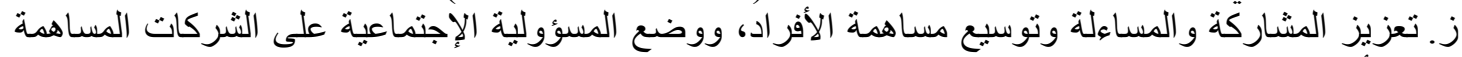

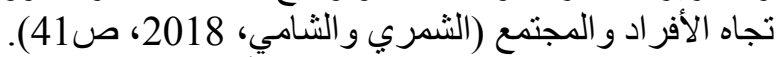

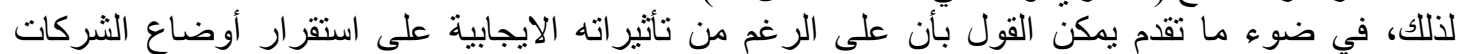

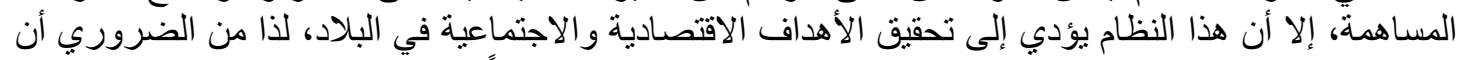

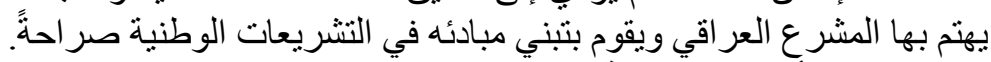

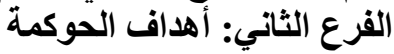

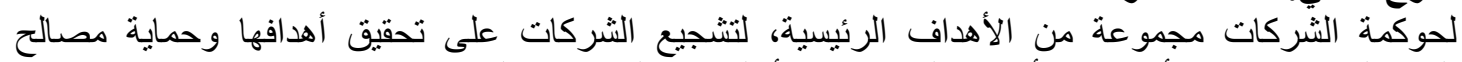

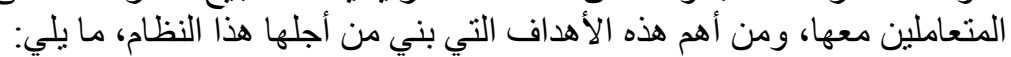

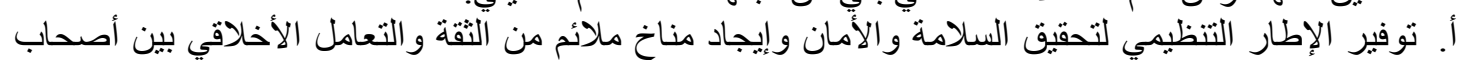

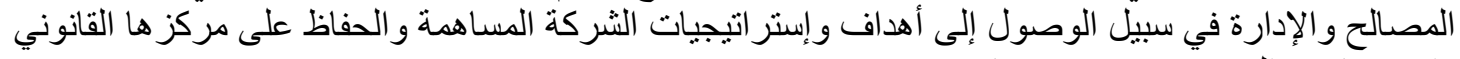

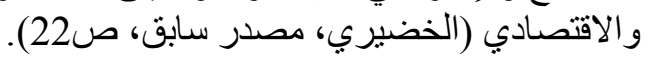




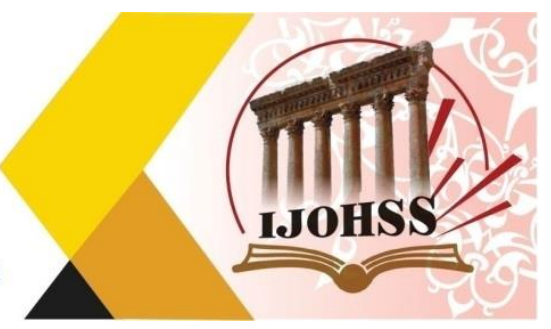

ب. وضع الضوابط والمعايير الخاصة لأعمال الثركات والأنظمة الكفيلة لتحقيق التنسيق الفعال وتطوير

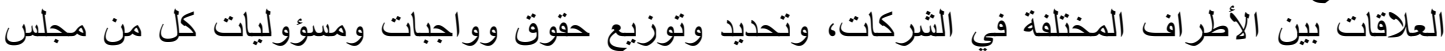

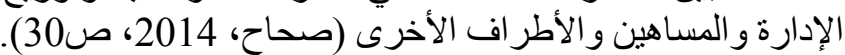

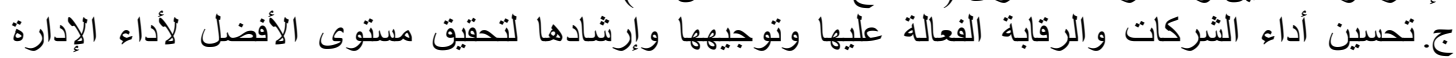

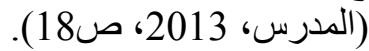

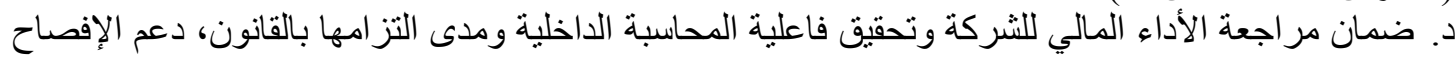

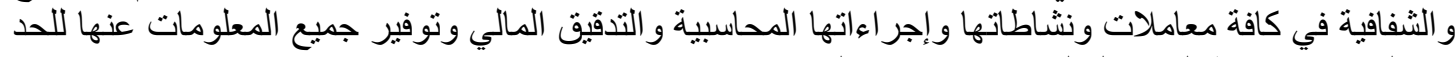

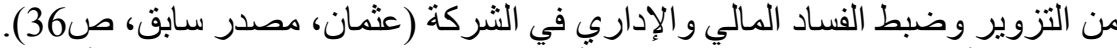

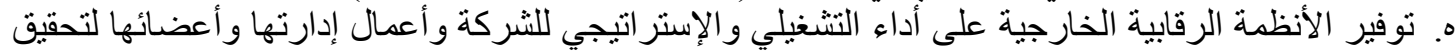

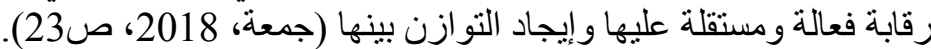
ز. تجنب حدوث الأزمات المالية وتخفيف آثار ها السيئة على أداء الثركات وحقوق الأفراد الثاد والاقتصاد الوطني

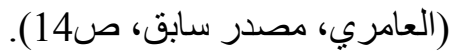

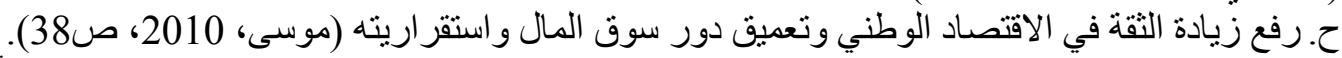

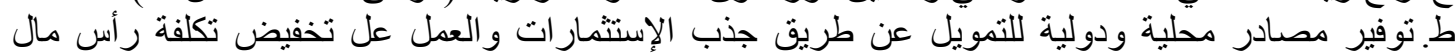

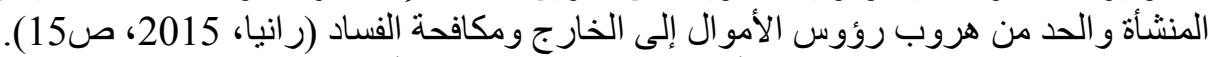

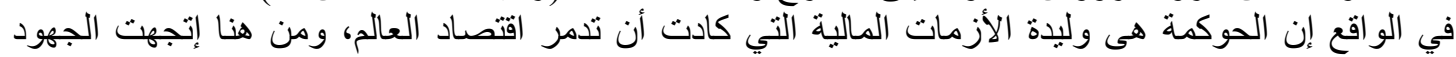

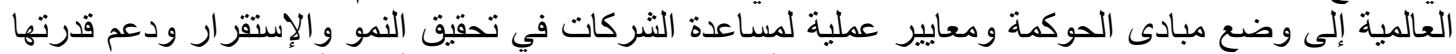

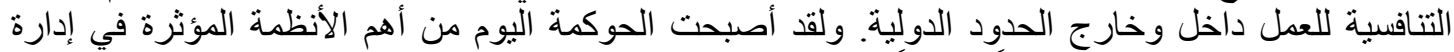

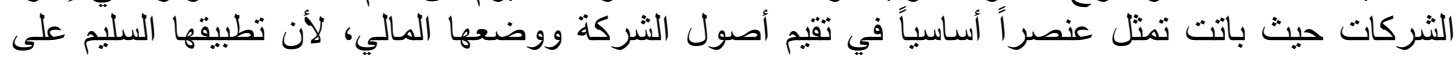

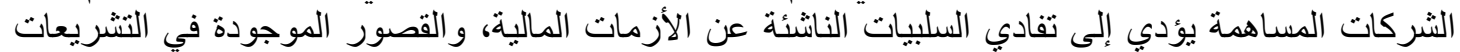

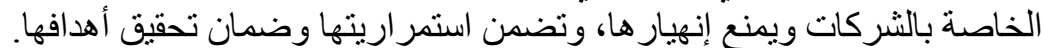

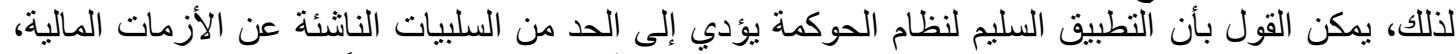

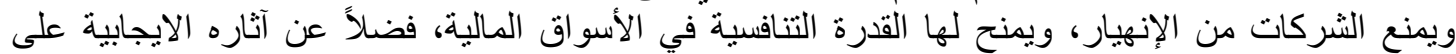

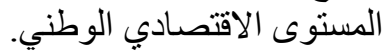

\section{المبحث الثاني}

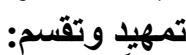

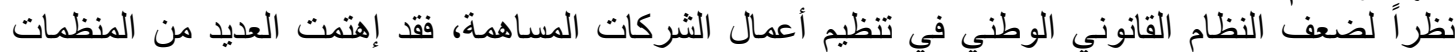

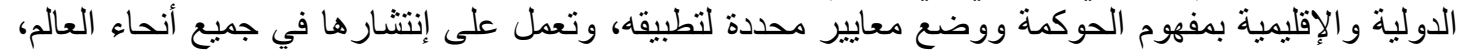

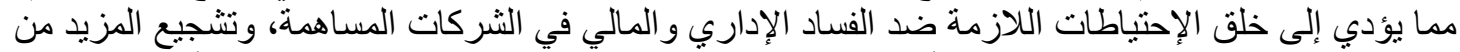

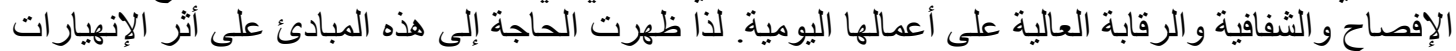

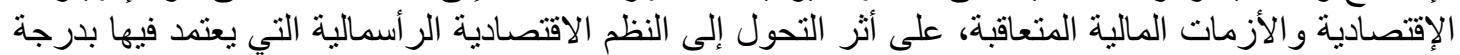

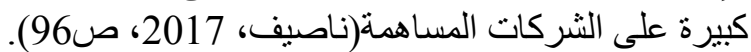

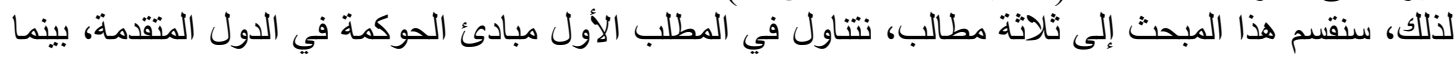
نخصص المطلب الثاني لدراسة مبادئ الحوكمة في الدول النامية، ثم نبحث طبيعة هذّة المبادئ في الدئ المطلب الثالث. المطلب الأول

مبادئ الحوكمة في تثريعات الدول المتقدمة

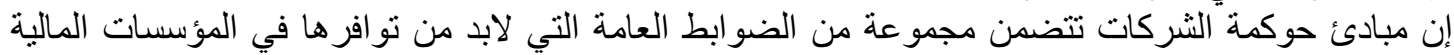

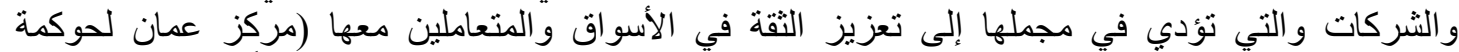
الثركات، 2011، ص44)، في البداية لقد اهتمت العديد من الدول المتقدمة بها، وخاصةً الولايات المتحدة 


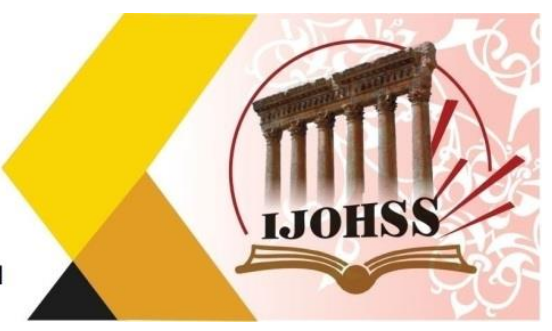

و المملكة المتحدة كآلية فعالة لإدارة شركاتهم المساهمة، وتحقيق أهدافها مع ضمان حقوق أطر اف ذات الصلة بها.

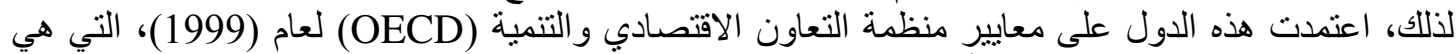

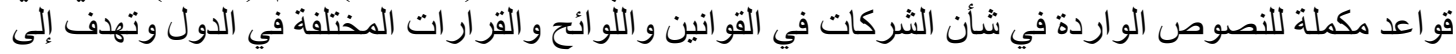

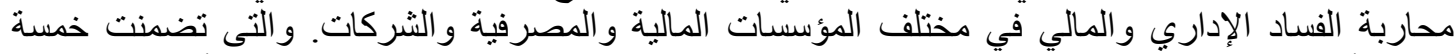

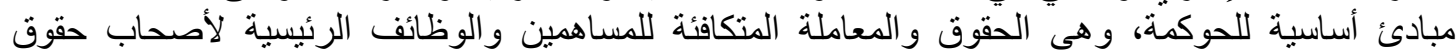

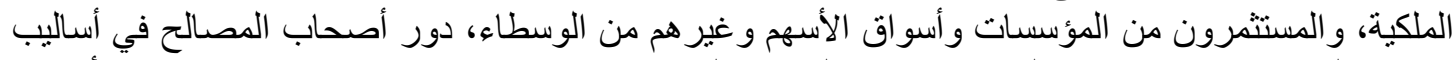

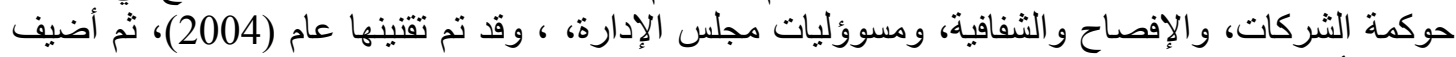
إليها مبدأ آخر عام (2015) وهو ضمان وات وجود إطار فعال لحوكمة الثركات (Www.oecd.org)، و إنتشرت

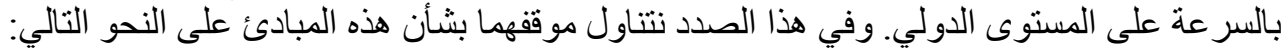
الفرع الأول: الولايات المتحدة الأمريكية الألية

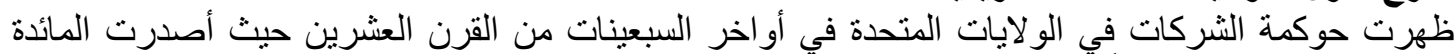

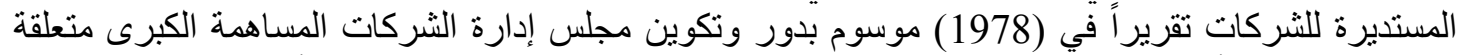

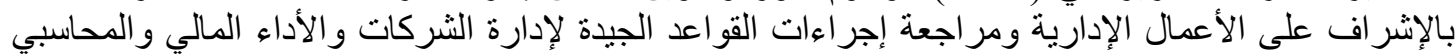

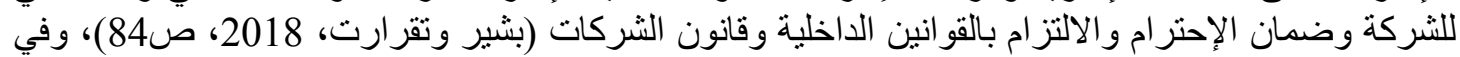

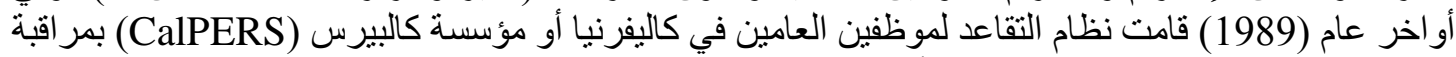

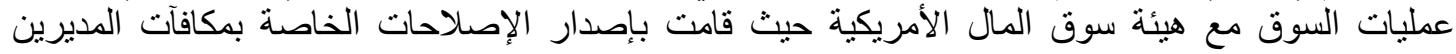

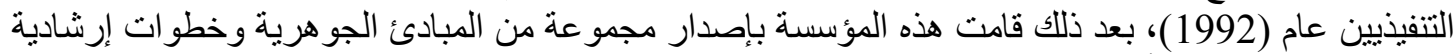

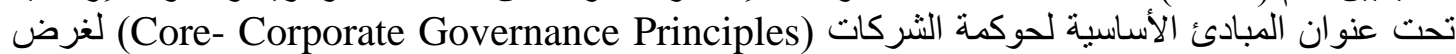

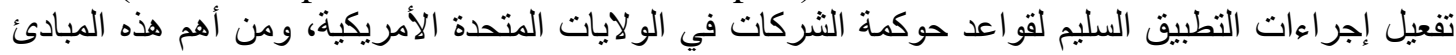

هي(www.boardoptioms.com)

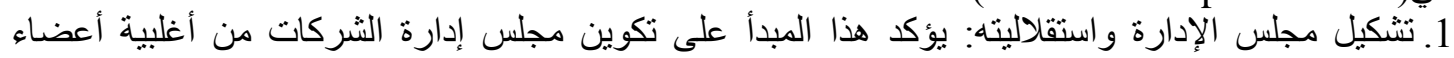

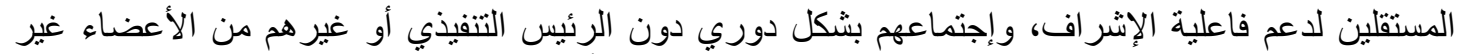

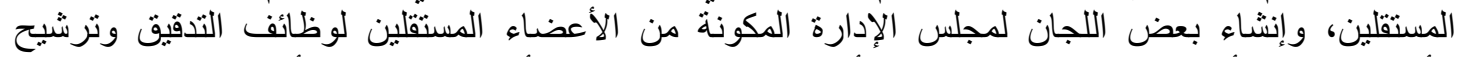

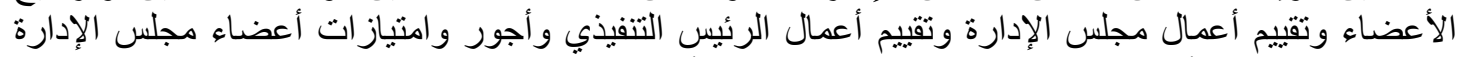

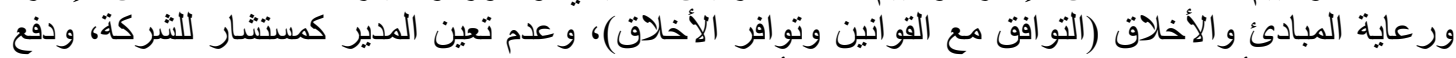

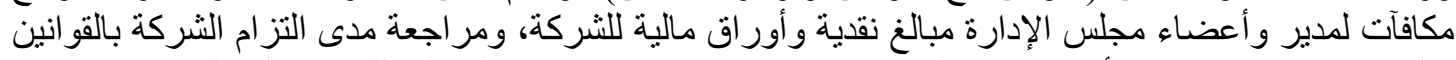

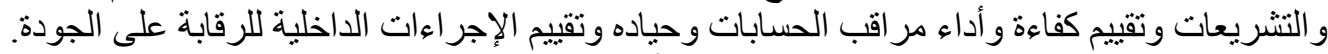

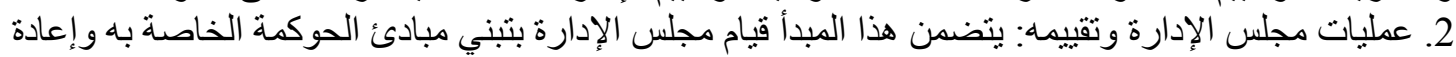

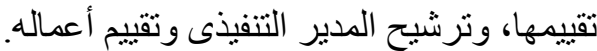

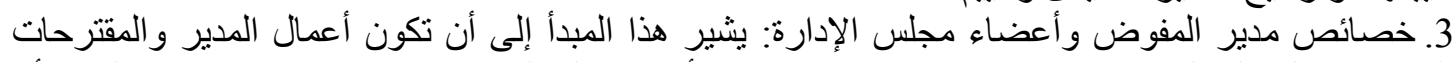

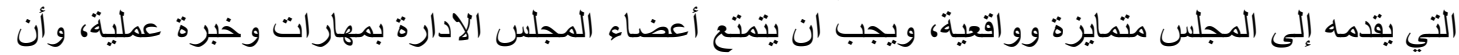

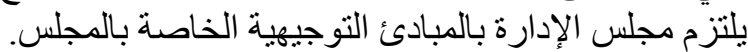
لقد تم إصدار تقرير (Treadway Commission) من جانب الإدارة اللجنة اللجنة الوطنية الخاصة في عام (1987) حول

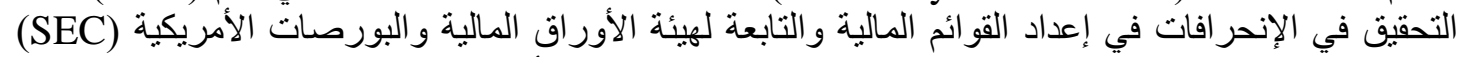

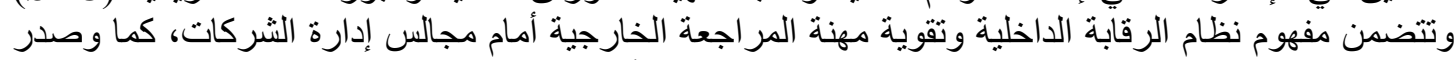

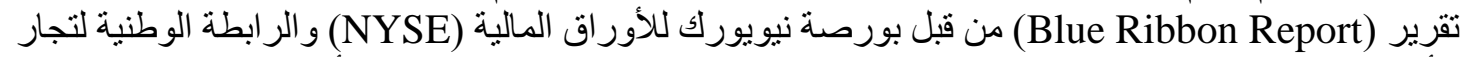

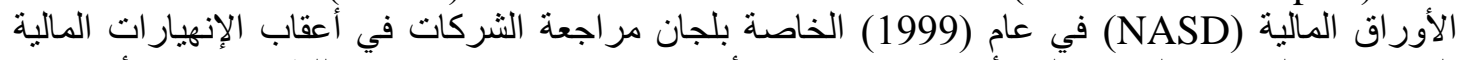

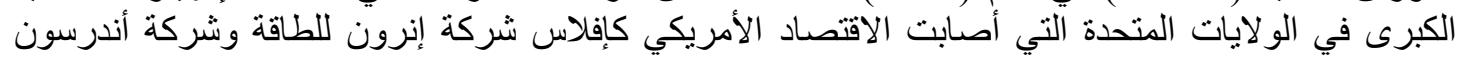

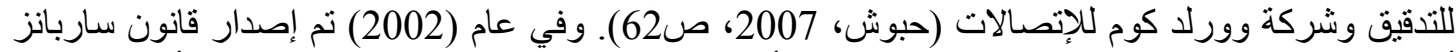

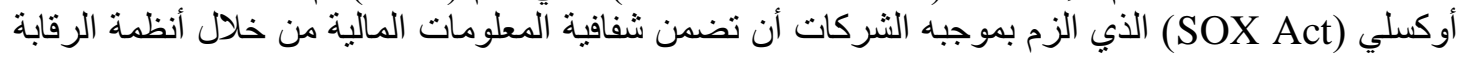

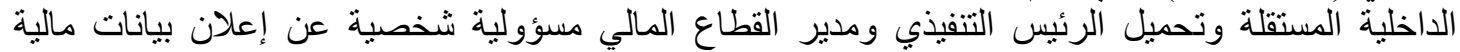
خاطئة، وذللك من أجل إعادة النظر في طرق إدارة الثركات ومراقبة أعمالها للقضاء على الثلى الفساد المالي

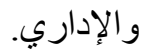


International Journal on Humanities and Social Sciences

website:www.ijohss.com

Email:editor@ijohss.com

العدد (27) نوفمبر 2021

ISSN: $2415-4822$

Volume (27) November 2021

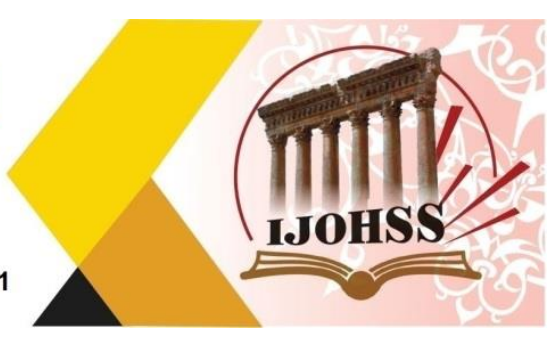

ومن خلال إلقاء الضوء على هذا القانون، يمكن القول بأن من أهم الأهداف التي بسعى إلى تحقيقه هي الثفافية

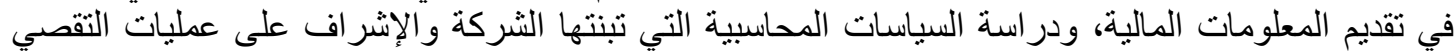

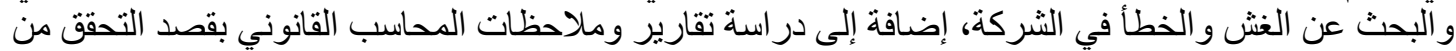

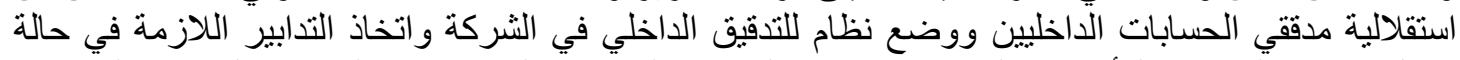

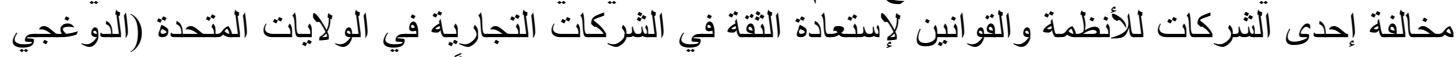

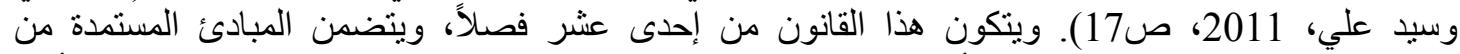

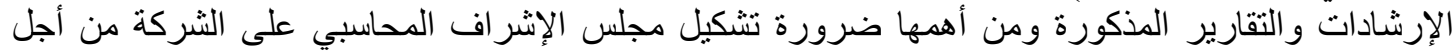

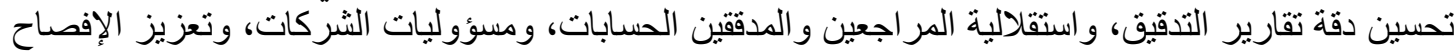

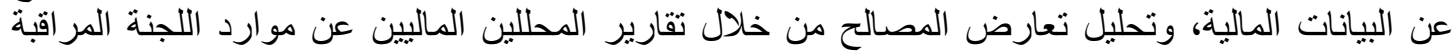

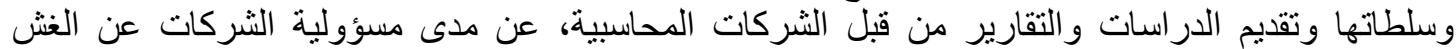

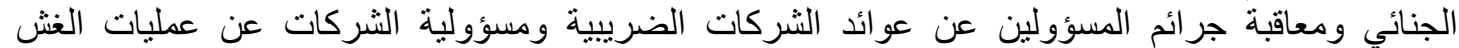

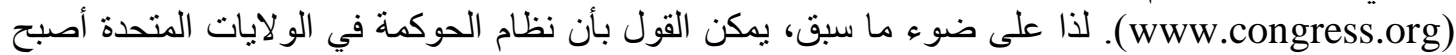

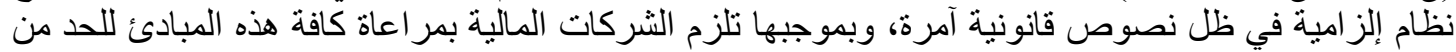
الغش و الفساد المالي فيها، من خلال الإفصاح و الثفافية في فو ائمها المالية وتفعيل الرقابة الثالية الداخلية والخارجية

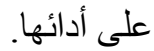
الفرع الثاني: المملكة المتحدة التمان

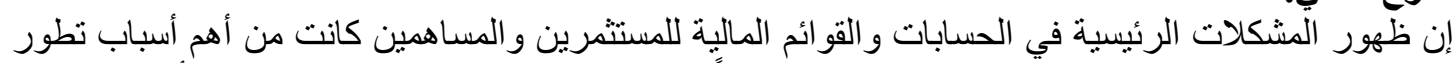

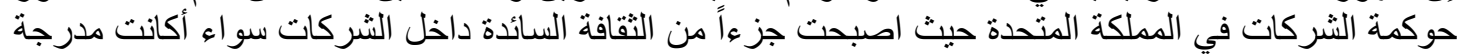

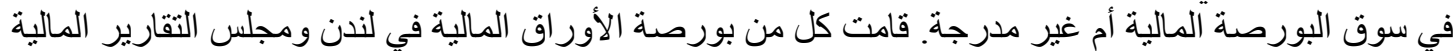

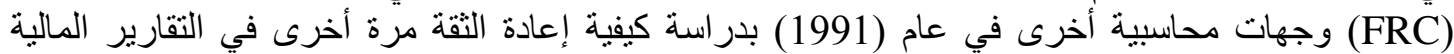

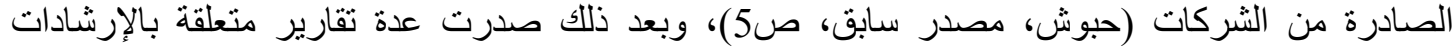

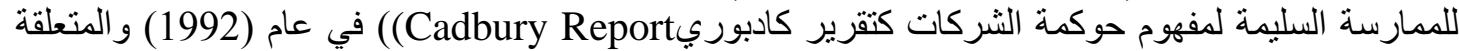

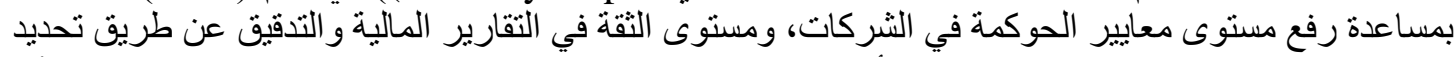

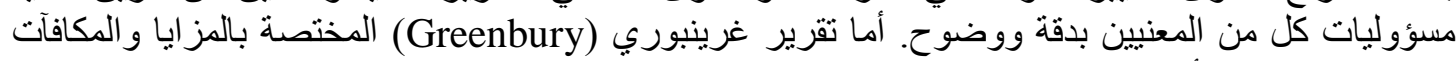

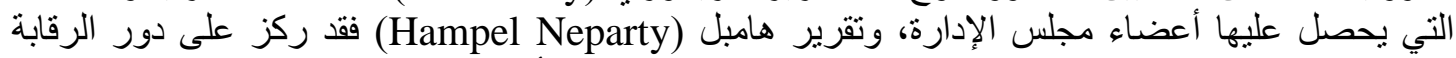

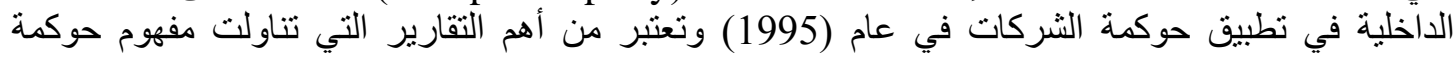

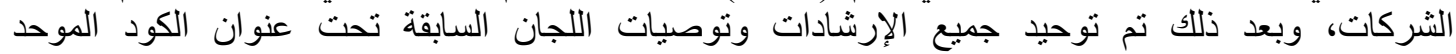
(Combined Code)

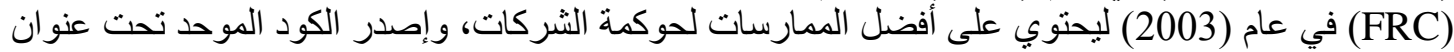
قانون حوكمة الثركات في الإنجلترا (Combined Code of Corporate Governance).

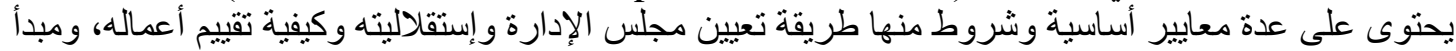

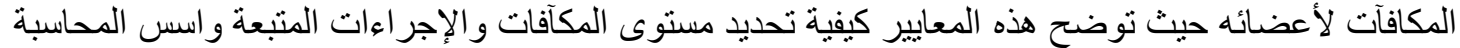

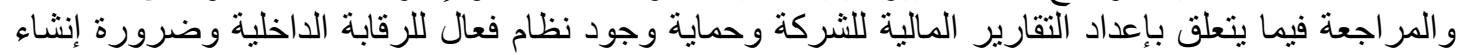

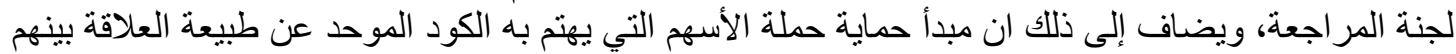

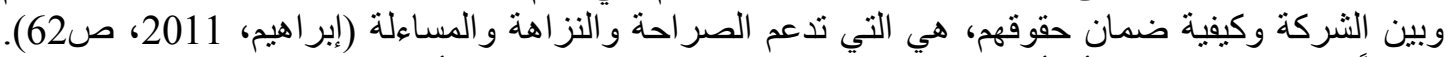

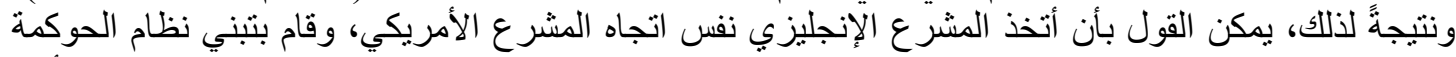

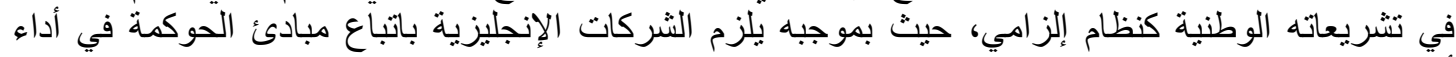
أعمالها وتقارير ها المالية و الإدارية.

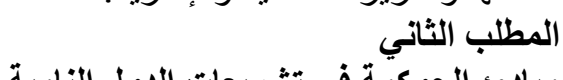
مبادئ الحوكمة في تثريعات الدول النامية

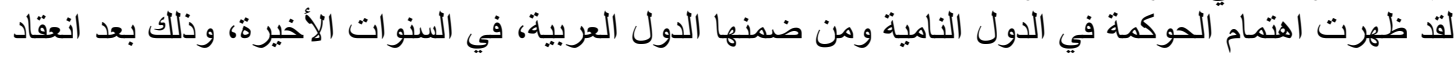

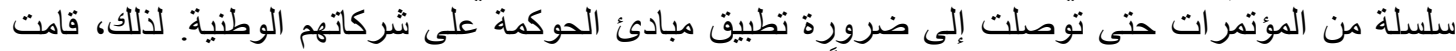

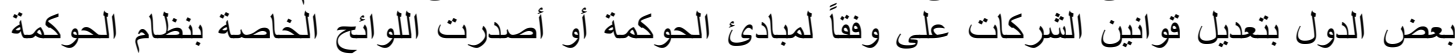


International Journal on Humanities and Social Sciences

website:www.ijohss.com

Email:editor@ijohss.com

العدد (27) نوفمبر 2021

ISSN: $2415-4822$

Volume (27) November 2021

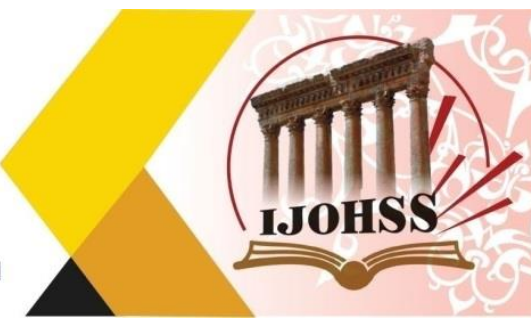

كقو اعد إلزامية، بينما اكتفت البعض منها بإصدار لو ائح ودليل إرشادي غير ملزم، وكي وكل هذا من أجل توثيق الثقة

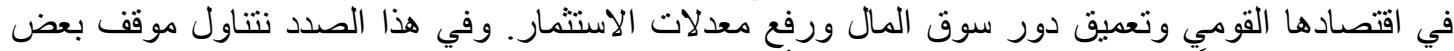

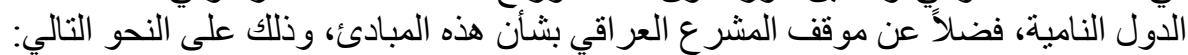

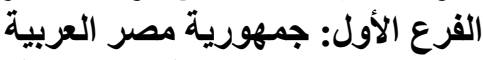

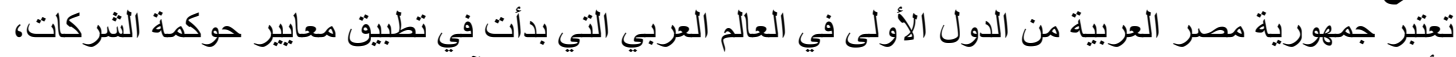

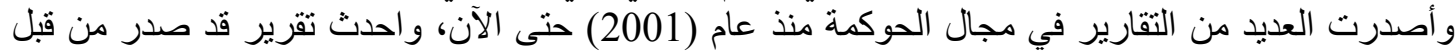

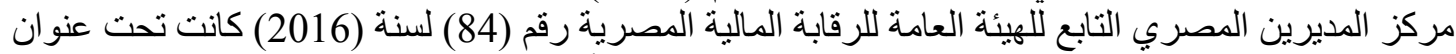

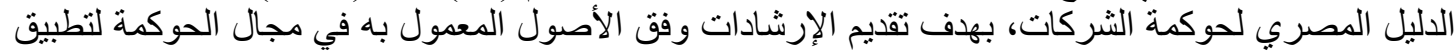

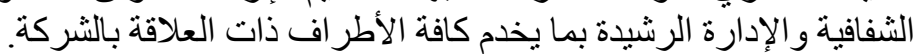

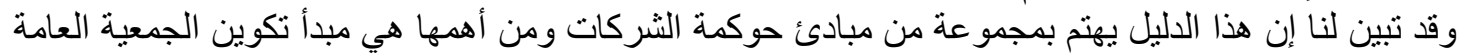

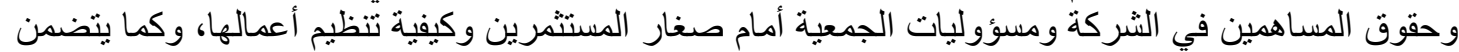

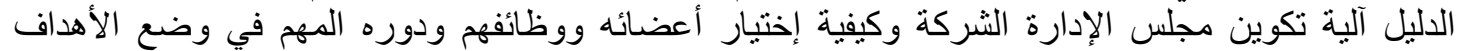

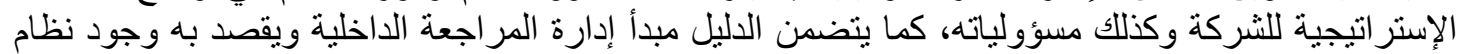

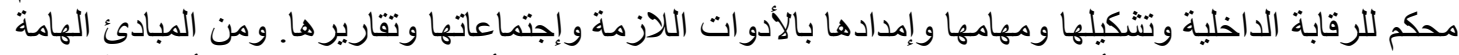

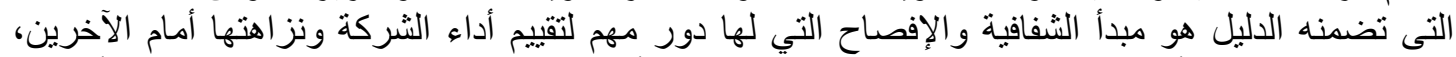

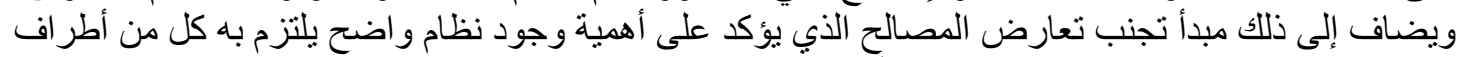

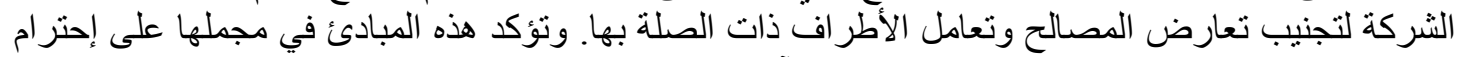

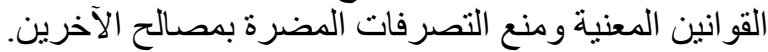

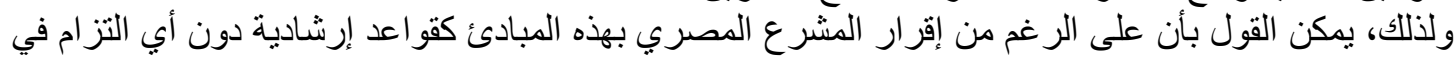

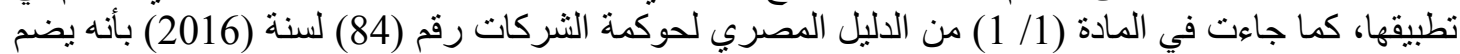

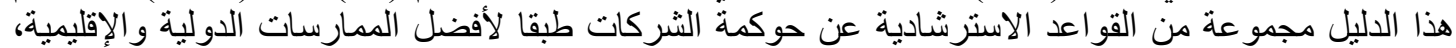

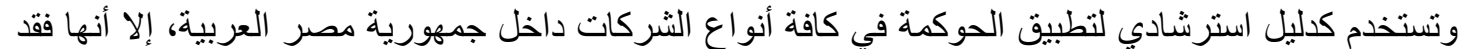

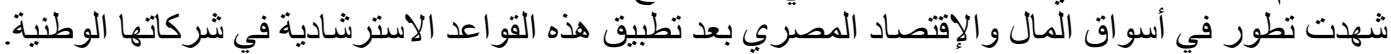

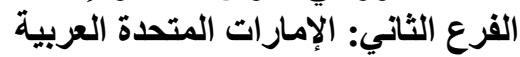

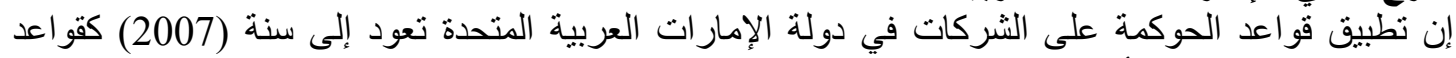

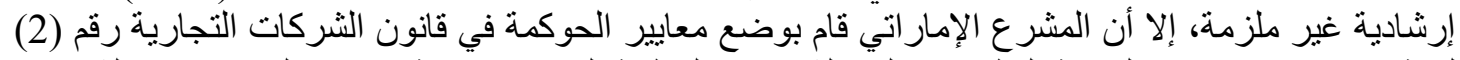

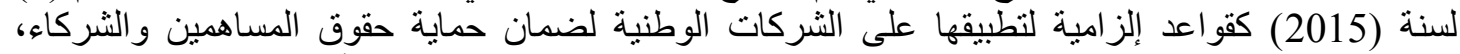

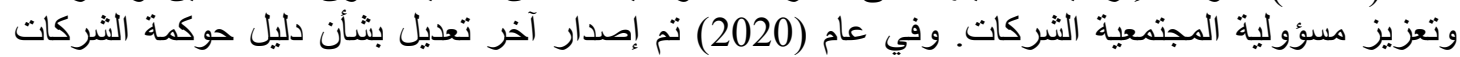

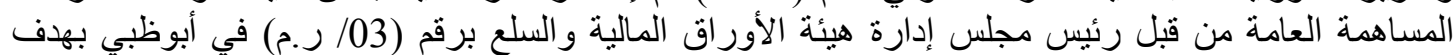

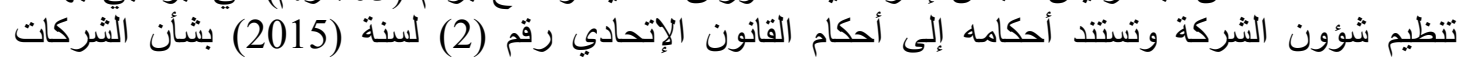

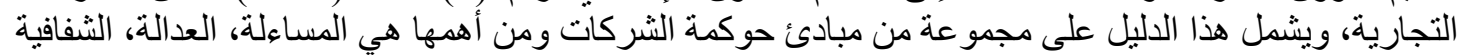

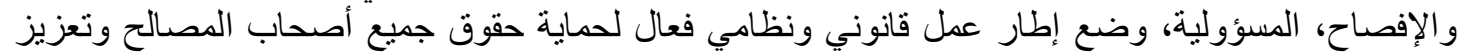

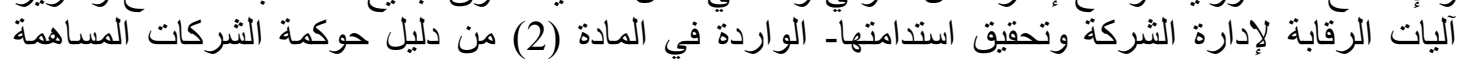

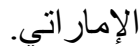

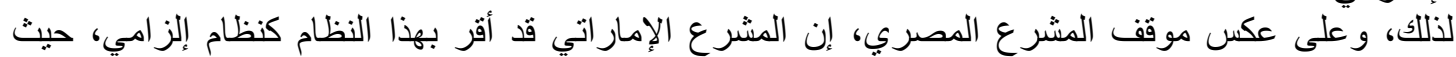

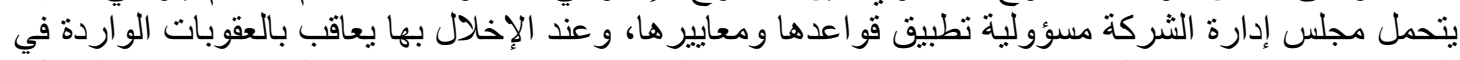

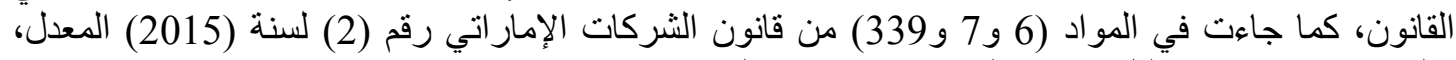

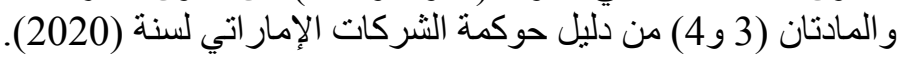

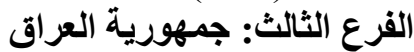

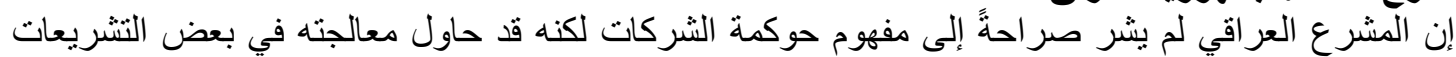

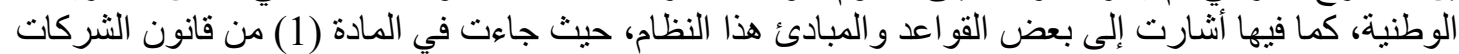

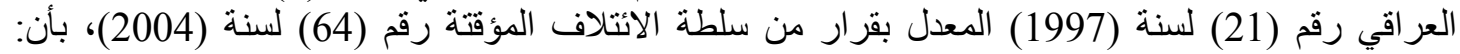

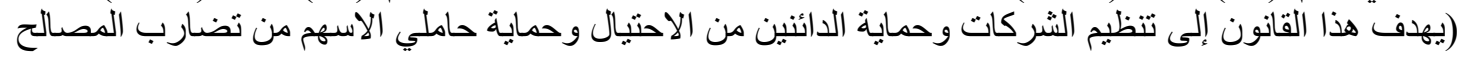


International Journal on Humanities and Social Sciences

website:www.ijohss.com

Email:editor@ijohss.com

العدد (27) نوفمبر 2021

ISSN: $2415-4822$

Volume (27) November 2021

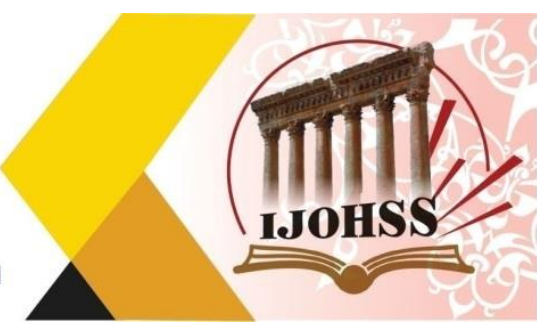

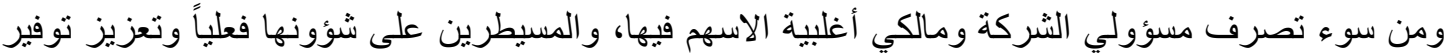

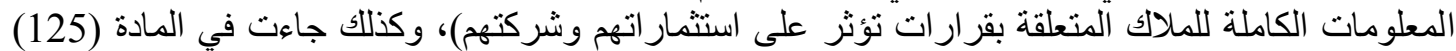

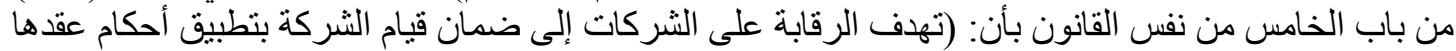

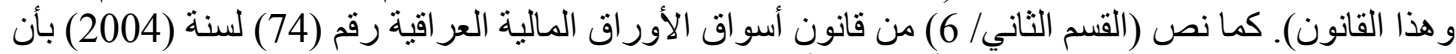

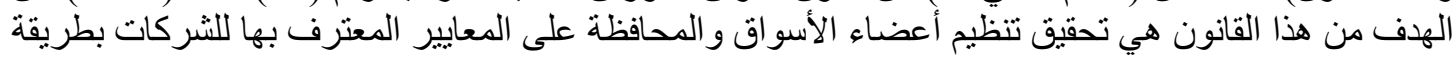

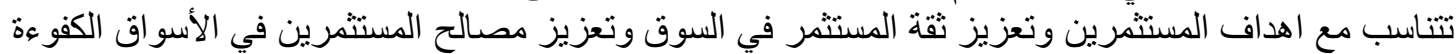

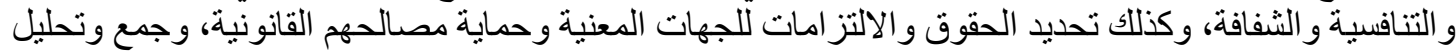

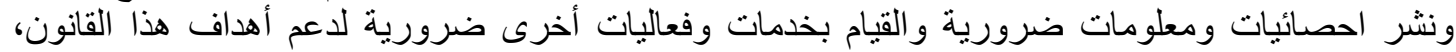

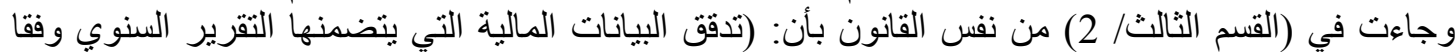

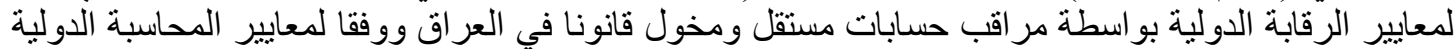

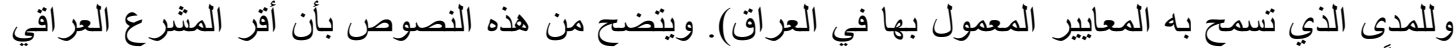

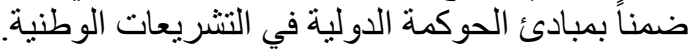

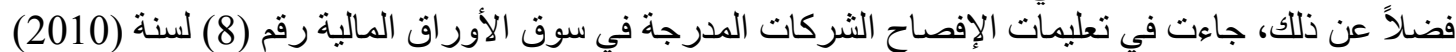

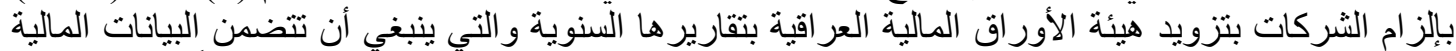

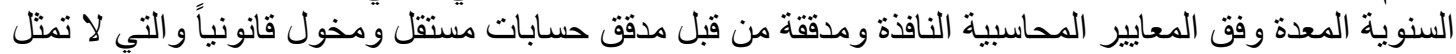

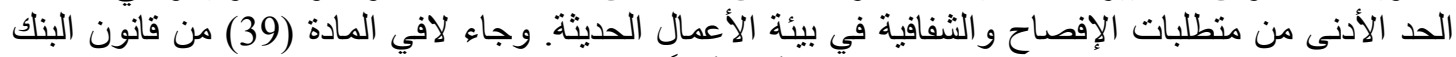

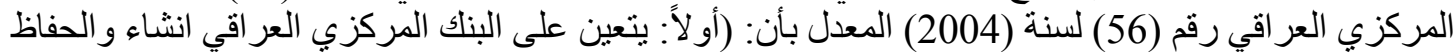

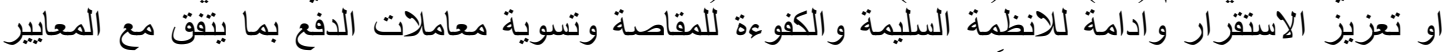

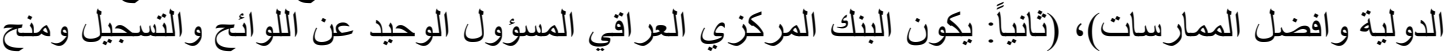

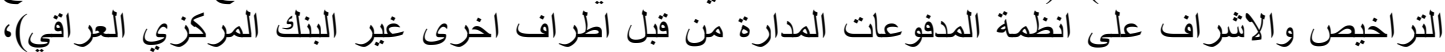

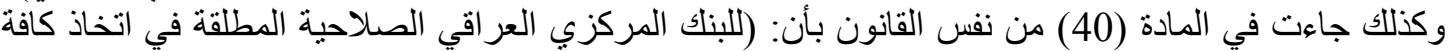

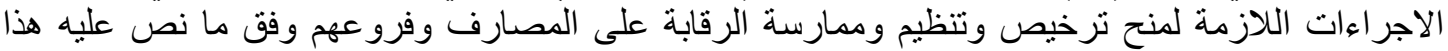

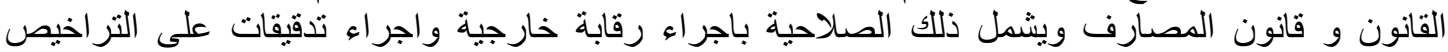

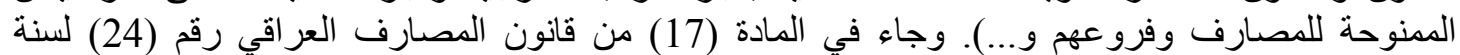

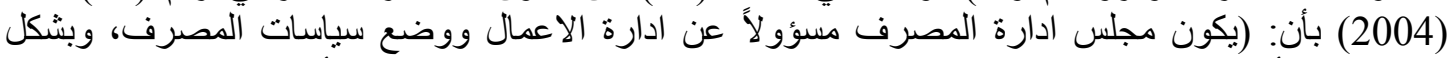

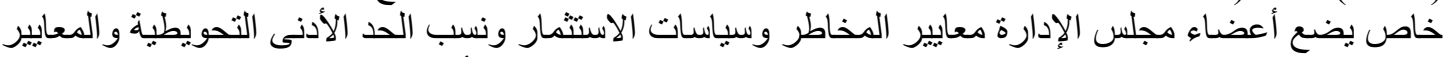

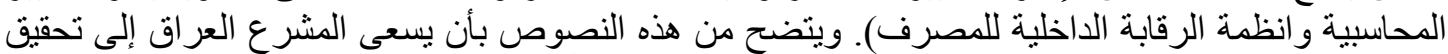

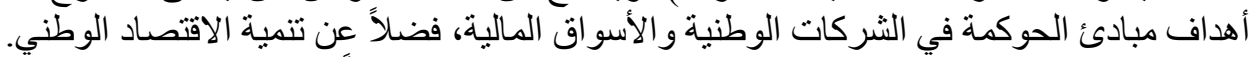

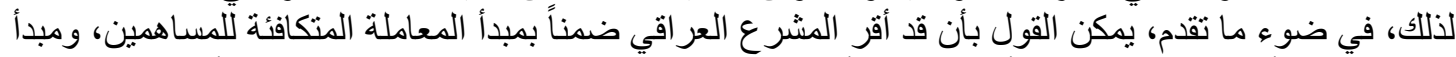

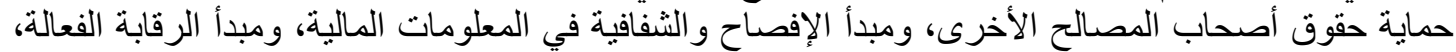

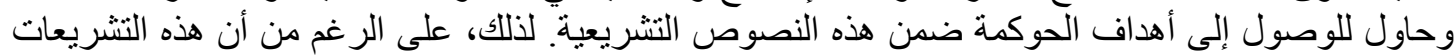

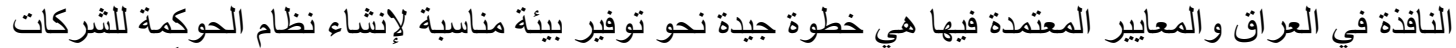

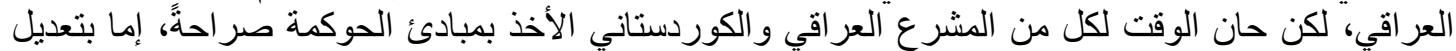

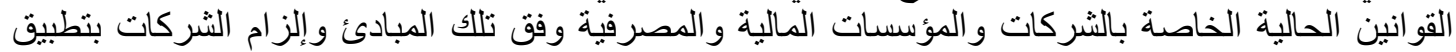

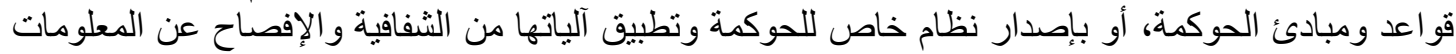

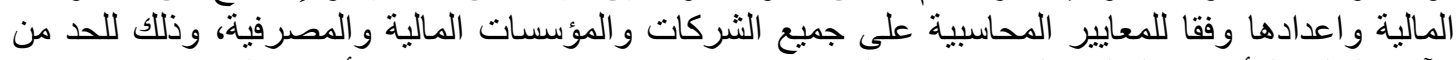

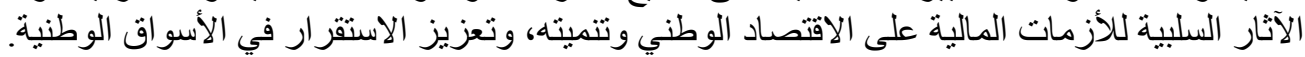

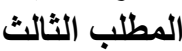
طبيعة مبادئ الحوكمة الحمبة تهدف مبادئ الحوكمة مساعدة الدول ولا سيما النامية في تحسين إطارهم القانونية المتعلقة بتنظيم أعمال

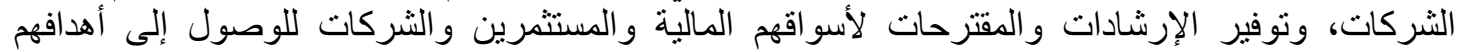

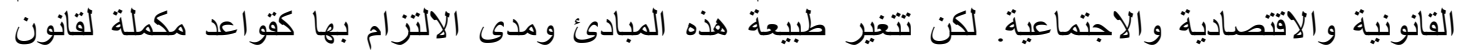
الشركات المساهمة من دولة إلى آخر، حيث البعض منها تعتبرها ها قواعد غير ملزمة الإلزمة للشركات من الناحية 


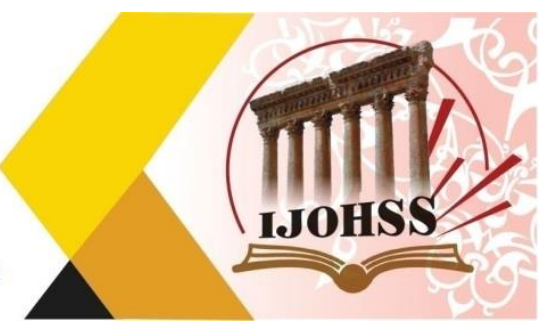

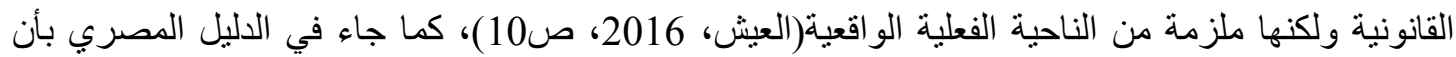

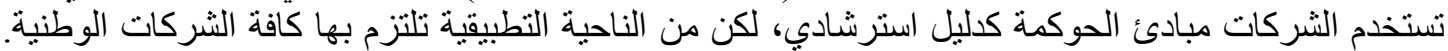

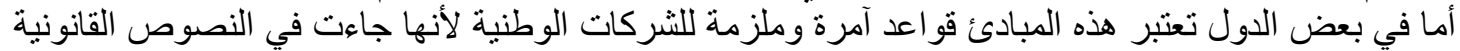

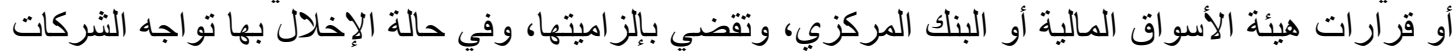

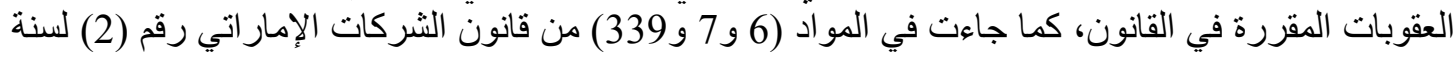

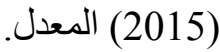

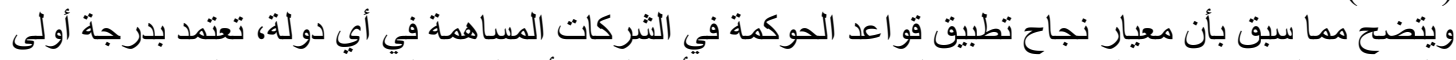

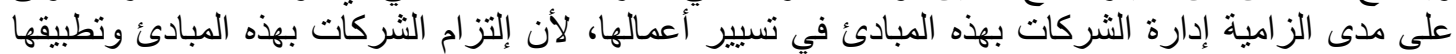

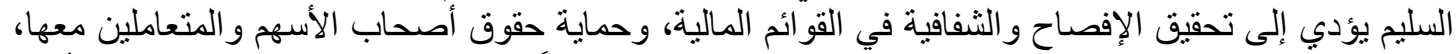

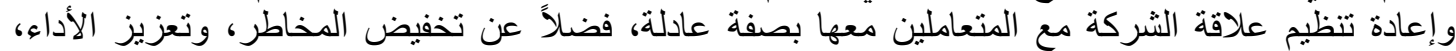

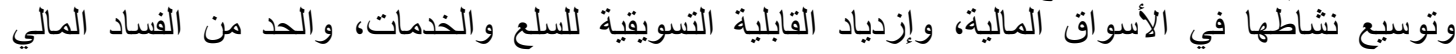
و الإداري وتحقيق المسؤولية الإجتماعية واستقرار السوق المالية والنمو الاقتصادي (عبود و الفتلاوي، 2016،

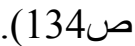

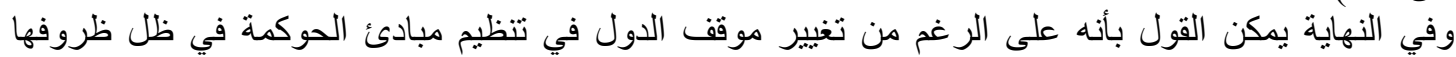

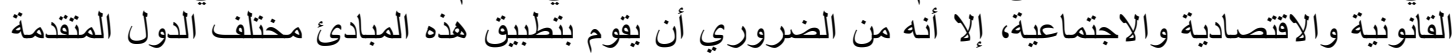

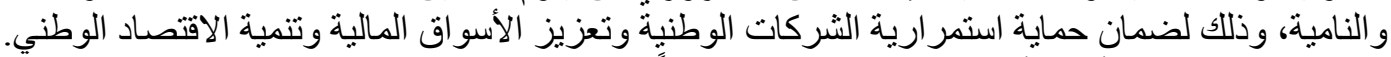

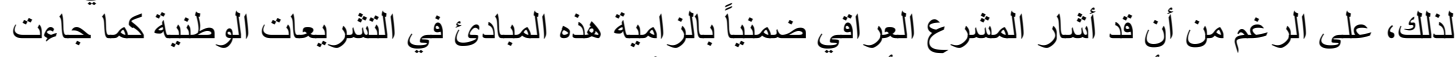

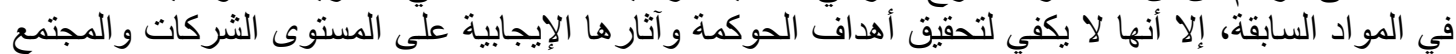

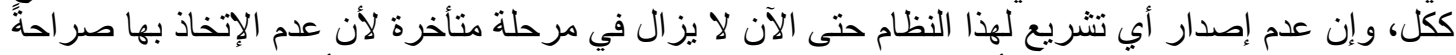

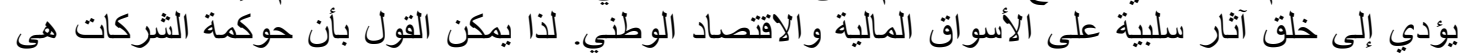

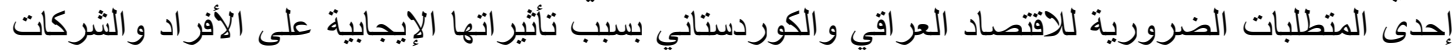

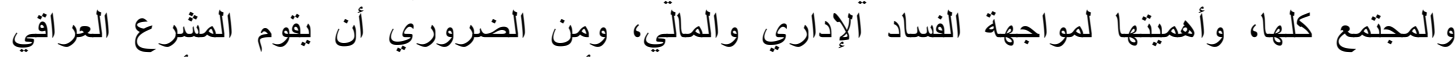

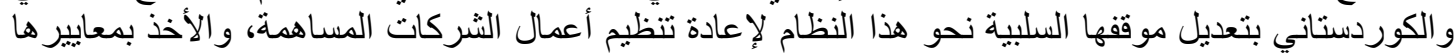
الدولية المعترفة بها على وجانه الإلتز ام.

الخاتمة في

في نهاية هذا البحث نورد بعضاً من النتائج و المقترحات التي توصلنا إليها من خلال الدراسة والتي نجمعها في

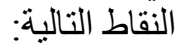

أولأ: الإستنتاجات

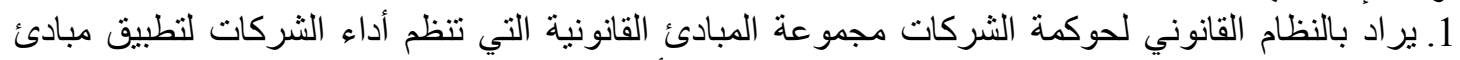

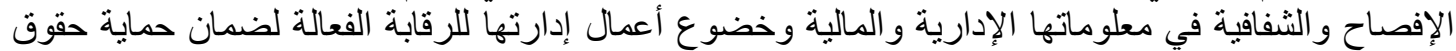

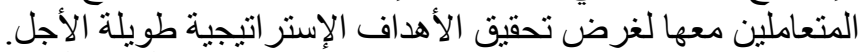

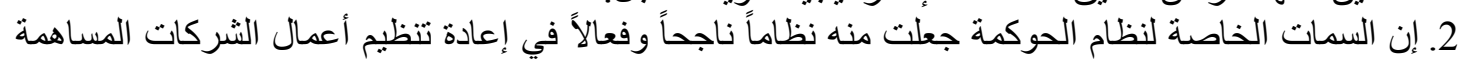

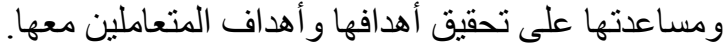

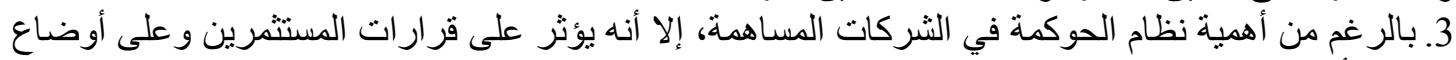

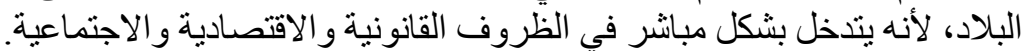

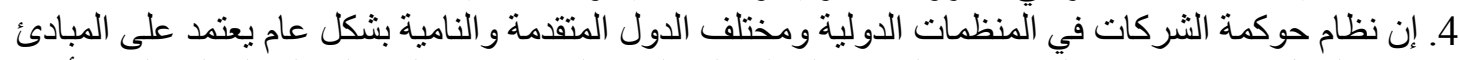

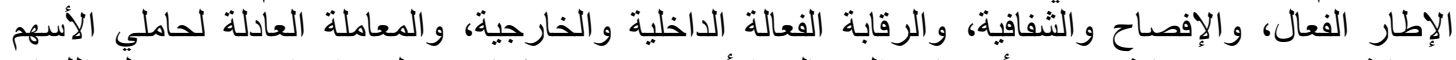

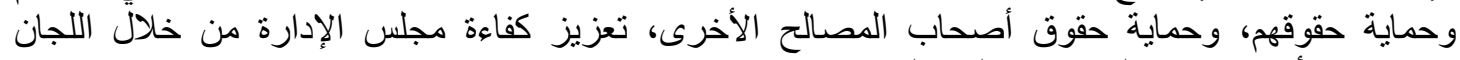
ومشاركة الأعضاء غير التنفيذيين و المستقلين فيها.

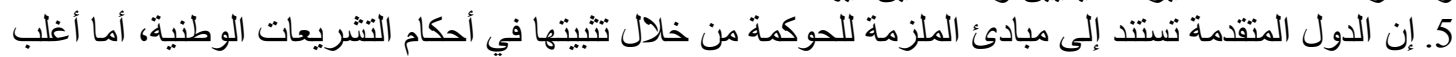
الدول النامية تعتمد على هذه المبادئ كقو اعد استرشادية لتطبيق الحوكمة في الثركات. 


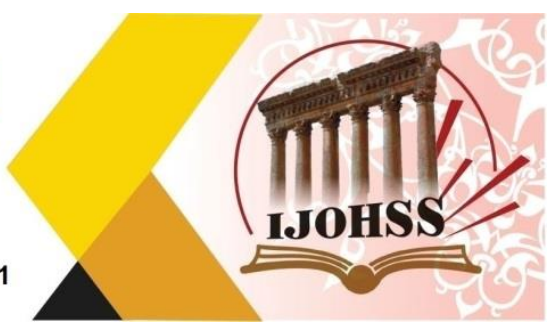

6. بالر غم من قو اعدها الالزامية أو الاختبارية، إلا أنها تلعب مبادئ الحوكمة دوراً كبيراً في إدارة الثركات

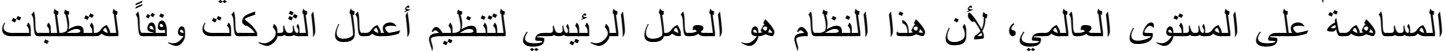

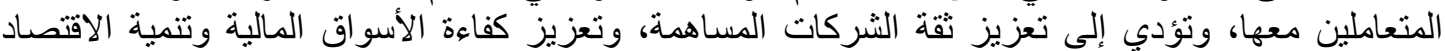
الوطني.

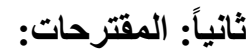

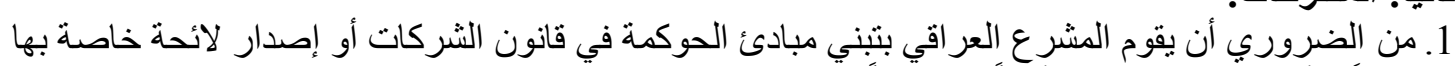

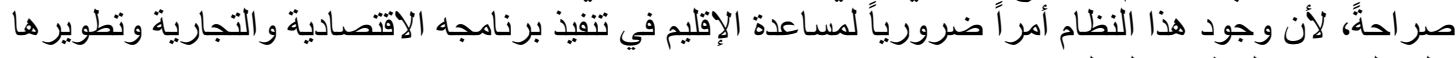
على المستوى الوطني و الدولي.

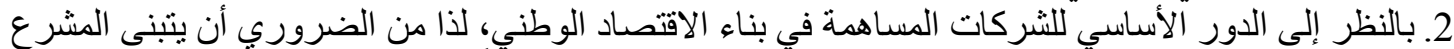

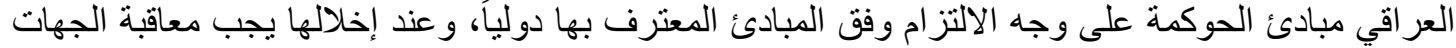
المسؤولة. 3. من الضروري أن توفر الجهات المعنية بيئة مناسبة و آمنة للشركات المساهمة و المستثمرين و المتعاملين معها من أجل تطوير ثنقافة تطبيق مبادئ الحوكمة في الدولة.

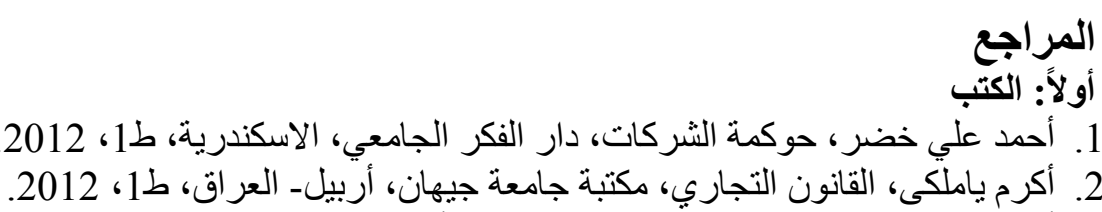

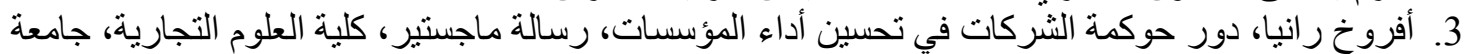
4حمد خيضر ، بسكرة، 4. إلهام مقدم، أثر تطبيق الحوكمة في القطاع المصرفي وفق مقررات لجنة بازل، رسالة ماجستير، كلية علوم

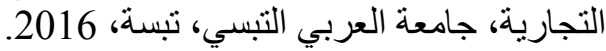
5. الياس ناصيف، حوكمة الثركات في القانون المقارن وتشريعات الدول العربية، منشورات الحلبي الحقوقية،

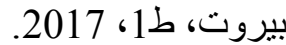
6. بن عيشي بشير ويزيد تقر ارت، حوكمة الثركات من منظور محاسبي، المكتب الجامعي الحديث، الإسكندرية، 2018

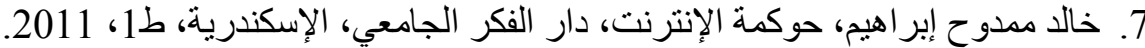

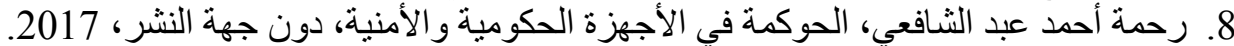
9. رضوان هاثم حمدون عثمان، التنظيم القانوني لحوكمة الثركات فيدة في التشريعات العربية، مركز الدرة الدراسات

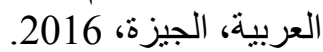

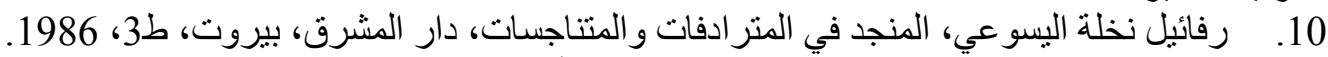
11.

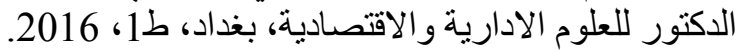

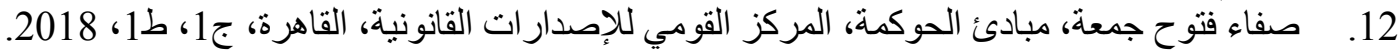
13. عصدت أنور صحاح، اتجاهات الحديثة في المراجعة وحوكمة البنوك، دار النشر للجامعات، القاهرة، . 2014 ، 14 14. عطاء الله وارد خليل، محمد عبد الفتاح العشماوي، الحوكمة المؤسسيةــ المدخل لمكافحة الفساد في

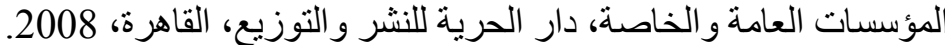

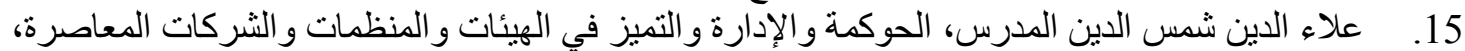

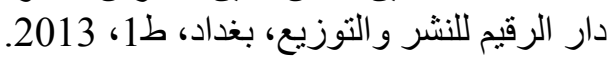
16. عمار حبيب جهلول، النظام القانوني لحوكمة الثركات، منشور ات زين الحقوقية، بيروت، ط1، 2011. 


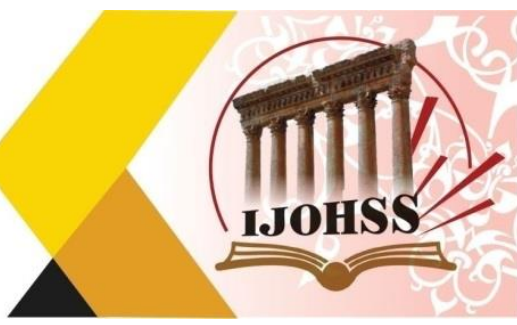

17. مايح شبيب الثمري وحسين علي الثامي، الحوكمة والنمو الاقتصادي، دار غيداء للنشر و التوزيع، عمان، .2018

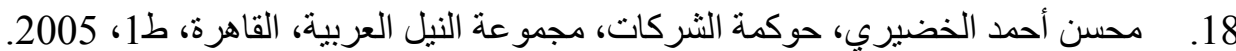

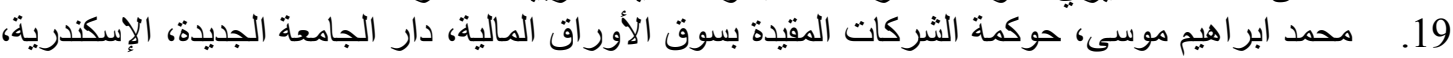

20. محمد بن حمد النصار، دور الحوكمة في الحد من ممارسات غسل الأموال في شركات التأمين، دار

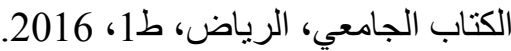

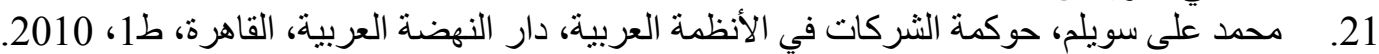

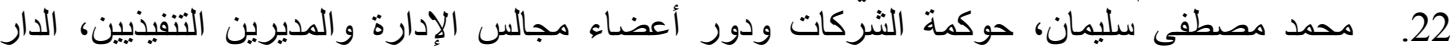

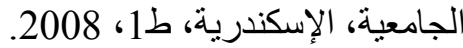
23. هادي بن علي محمد الليامي، الالتزام بالإفصاح و الثنفافية في نظام حوكمة الثركات السعودي، دار

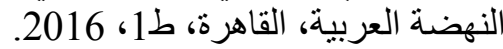
24. هياء بنت دخيل الله المريبض، مسيض، الفؤولية أعضاء مجلس إدارة شركات المساهمة في إطار حوكمة الثركات

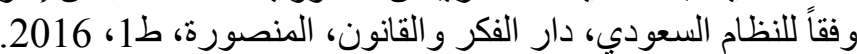

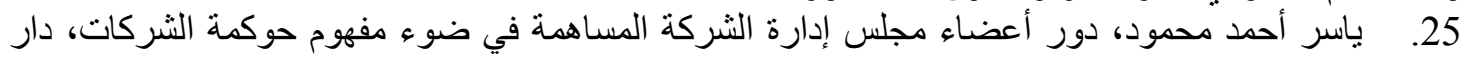
النهضة العربية، القاهرة، 2016. ثانياً: الرسائل

26. سلامة حمود العامري، قوائل العد الحوكمة في الثركات المساهمة في دولة الإمارات العربية المتحدة، رسالة

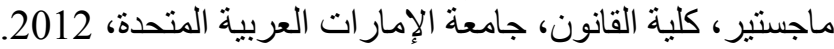

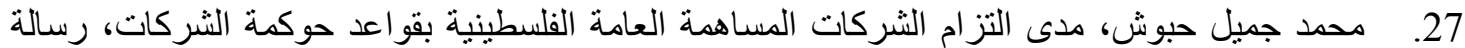

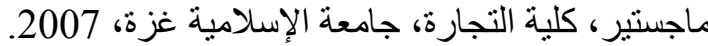
ثالثاً: البحوث كلثة

28. الصالحين محمد العيش، حوكمة الثركات بين القانون واللائحة، المجلة الدولية للقانون، كلية القانون، جامعة بنغازي، 29. علي حسين الدوغجي، وأسامة عبد المنعم سيد علي، دور قانون (ساربينز - أوكسلي) في رفع كفاءة مهنة

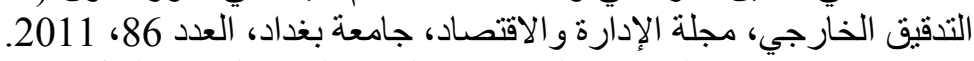

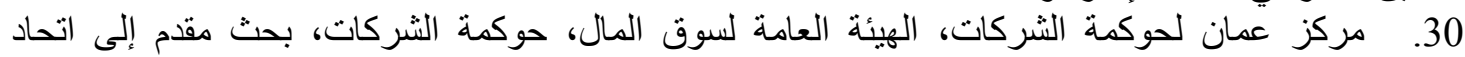
الثركات الاستثمارية، الكويت، رابعاً: القوانين 31 31. قانون الثركات العر اقي رقم (21) لسنة (1997) المعدل. 32. 31 دليل حوكمة الشركات المصرية الصادرة عن هيئة الأوراق العامة للرقابة المالية رقم (84) لسنة

$$
\text { 33. قانون الشركات الإمار اتي رقم (2) لسنة (2015). }
$$

34. دليل حوكمة الثركات التساهمة العامة الإماراتية الصادرة (2015 عن مجلس إدارة الهيئة رقم (03/ر.م) لسنة 